\title{
PD-1+CD8+ $T$ cells are clonally expanding effectors in human chronic inflammation
}

\author{
Alessandra Petrelli, ${ }^{1}$ Gerdien Mijnheer, ${ }^{1}$ David P. Hoytema van Konijnenburg, ${ }^{1,2}$ Maria M. van der Wal, ${ }^{1}$ Barbara Giovannone, ${ }^{3}$ \\ Enric Mocholi, ${ }^{4}$ Nadia Vazirpanah, ${ }^{5}$ Jasper C. Broen, ${ }^{5}$ Dirkjan Hijnen, ${ }^{3}$ Bas Oldenburg, ${ }^{6}$ Paul J. Coffer, ${ }^{4}$ Sebastian J. Vastert, ${ }^{7}$ \\ Berent J. Prakken, ${ }^{7}$ Eric Spierings, ${ }^{1}$ Aridaman Pandit, ${ }^{5}$ Michal Mokry, ${ }^{8,9}$ and Femke van Wijk ${ }^{7}$ \\ 'Laboratory of Translational Immunology, University Medical Center Utrecht, Utrecht, Netherlands. ${ }^{2}$ Laboratory of Mucosal Immunology, The Rockefeller University, New York, New York, USA. ${ }^{3}$ Department of \\ Dermatology and Allergology, ${ }^{4}$ Department of Cell Biology, Center for Molecular Medicine, ${ }^{5}$ Department of Rheumatology and Clinical Immunology, ${ }^{6}$ Department of Castroenterology and Hepatology, and \\ 7Department of Pediatrics, Laboratory of Translational Immunology, University Medical Center Utrecht, Utrecht, Netherlands. ${ }^{8}$ Department of Pediatric Gastroenterology, Division of Child Health, Wilhelmina \\ Children's Hospital, Utrecht, Netherlands. ${ }^{~}$ Regenerative Medicine Center Utrecht, University Medical Center Utrecht, Utrecht, Netherlands.
}

\begin{abstract}
Chronic inflammatory diseases are characterized by recurrent inflammatory attacks in the tissues mediated by autoreactive T cells. Identity and functional programming of $C D 8^{+} \mathrm{T}$ cells at the target site of inflammation still remain elusive. One key question is whether, in these antigen-rich environments, chronic stimulation leads to CD8+ $T$ cell exhaustion comparable to what is observed in infectious disease contexts. In the synovial fluid (SF) of juvenile idiopathic arthritis (JIA) patients, a model of chronic inflammation, an overrepresentation of PD-1+CD8 $T$ cells was found. Gene expression profiling, gene set enrichment analysis, functional studies, and extracellular flux analysis identified $\mathrm{PD}-1^{+} \mathrm{CD} 8^{+} \mathrm{T}$ cells as metabolically active effectors, with no sign of exhaustion. Furthermore, PD-1+CD8+ $T$ cells were enriched for a tissue-resident memory (Trm) cell transcriptional profile and demonstrated increased clonal expansion compared with the PD-1- counterpart, suggesting antigen-driven expansion of locally adapted cells. Interestingly, this subset was also found increased in target tissues in other human chronic inflammatory diseases. These data indicate that local chronic inflammation drives the induction and expansion of $\mathrm{CD8}^{+} \mathrm{T}$ cells endowed with potential detrimental properties. Together, these findings lay the basis for investigation of PD-1-expressing CD8+ $\mathrm{T}$ cell targeting strategies in human chronic inflammatory diseases.
\end{abstract}

\section{Introduction}

Chronic inflammatory diseases, such as inflammatory bowel disease (IBD), juvenile idiopathic arthritis (JIA), and atopic dermatitis (AD), are heterogeneous clinical disorders representing a major public health issue (1). Current treatments suppress but do not cure disease, and there is still a fundamental gap in our understanding of how inflammation persists. Assessment of the immunological profile in the peripheral blood ( $\mathrm{PB}$ ) may provide only a partial picture of the mechanisms triggering and maintaining organ-specific chronic inflammation. Local $\mathrm{T}$ cells may play a major role in the development of disease chronicity; however, identity and dynamics of $\mathrm{T}$ cells as well as their functional differentiation in local inflammatory environments are still largely unexplored. $\mathrm{CD}^{+} \mathrm{T}$ cells have all of the features that can potentially play a key role in inflamed tissues: they can be cytotoxic and proinflammatory, react to self-antigens upon crosspresentation, develop regulatory properties, and be retained and maintained in the tissues (2). However, for a long time, $\mathrm{CD}^{+} \mathrm{T}$ cells have been neglected in chronic inflammatory diseases, and their functional programming at the target site of inflammation has yet to be investigated.

Conflict of interest: The authors have declared that no conflict of interest exists Submitted: July 7, 2017; Accepted: July 26, 2018.

Reference information: J Clin Invest. 2018;128(10):4669-4681.

https://doi.org/10.1172/JCI96107.
An overrepresentation of the $\mathrm{CD}^{+} \mathrm{T}$ cell subset is found in the brain of multiple sclerosis (MS) patients (3) and the synovium of patients with rheumatoid arthritis (RA) (4), JIA (5), and psoriatic arthritis (PsA) (6). In this study, as a model for investigating inflammation-instructed $\mathrm{CD}^{+} \mathrm{T}$ cell functional specialization, we used the target site of inflammation of JIA (i.e., the synovium). Synovial fluid-derived (SF-derived) $\mathrm{CD}^{+} \mathrm{T}$ cells have been shown to display a mixed pro- and antiinflammatory phenotype $(4,7)$ as well as intrinsic resistance to regulation by Tregs $(8,9)$. Additionally, these $\mathrm{T}$ cells upregulate negative costimulatory markers, such as PD-1 and TIM-3 $(4,10)$, typically overexpressed in environments characterized by chronic antigen-driven stimulation (11). Upregulation of negative costimulation on $\mathrm{CD}^{+} \mathrm{T}$ cells, indeed, has been previously associated with exhaustion, meaning loss of effector function, in cancer as well as infectious diseases $(11,12)$. In this context, effector functions can be restored via PD-1/PD-L1 pathway inhibition $(13,14)$, and this is confirmed by the evidence that anti-PD-L1 agents are considered promising therapies in a wide range of malignancies (15). PD-1 expression has been shown to be elevated on $\mathrm{T}$ cells obtained from the SF of patients with inflammatory (4), but not nonautoimmune, arthritis (i.e., osteoarthritis) (16), raising the question of whether this subset represents an effector rather than a functionally impaired cell subset. However, in chronic inflammatory diseases, it appears counterintuitive for PD $-1^{+} \mathrm{CD} 8^{+}$ $\mathrm{T}$ cells to be impaired in function and cytotoxic activity, given that they derive from the site with actively ongoing inflammation. 

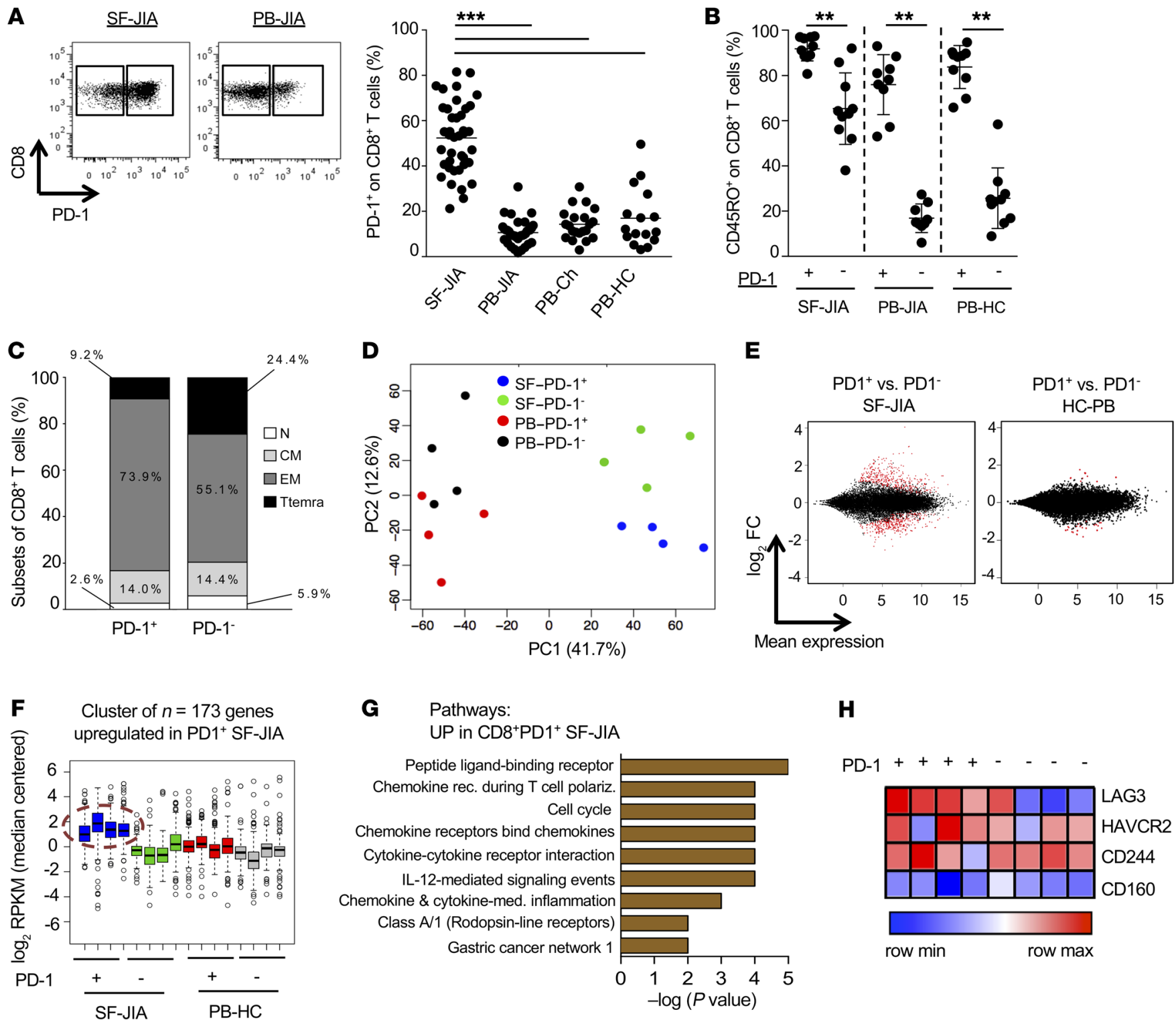

Figure 1. PD1-expressing CD8 ${ }^{+} T$ cells are highly activated at the target site of inflammatory arthritis. (A) PD-1 expression on CD8 $8^{+} \mathrm{T}$ cells is shown at the site of inflammation of JIA patients (i.e., the SF), PB-JIA, PB-Ch, and PB-HC. Representative dot plots are shown in the left panel. Data are shown as mean \pm SD. ${ }^{* *} P<0.0001$, 1-way ANOVA. (B) CD45R0 expression on PD-1+ and PD-1-CD8 ${ }^{+} T$ cells in indicated samples. Data are shown as mean \pm SD. ${ }^{*} P<0.01$, paired Student's $t$ test. (C) PD-1 $1^{+}$and PD-1-CD8 ${ }^{+}$T cell differentiation is shown by using CD45RA and CCR7 markers. Data are shown as mean from 6 SF-JIA samples. (D) PD-1+ and PD-1-CD8+ T cells were sorted from SF-JIA and PB-HC. Clustering of SF vs. PB PD-1+ and PD-1-CD8 ${ }^{+}$T cells by PCA is shown. (E) Differentially expressed genes (red dots) between $\mathrm{PD}-1^{+}$and $\mathrm{PD}-\mathrm{1}^{-} \mathrm{CD} 8^{+} \mathrm{T}$ cells in SF and $\mathrm{PB}$ are depicted in MA plots. (F) K-means analysis identifies a set of genes specifically upregulated in PD-1+CD8 ${ }^{+} T$ cells from SF. (C) Pathways specifically enriched in PD-1+CD8 ${ }^{+} T$ cells from SF are listed. rec, receptors; polariz., polarization; med., mediated. (H) The heatmap shows color-coded gene expression levels of negative costimulatory markers typically upregulated in exhausted CD8 ${ }^{+} \mathrm{T}$ cells in PD-1 ${ }^{+}$and PD-1 $\mathrm{CD}^{+}$T cells from SF. UP, upregulated; N, naive (CD45RA+CCR7+); CM, (CD45RA-CCR7+); EM, effector memory (CD45RA-CCR7-); Ttemra, (CD45RA+CCR7-).

In this study, by using several different techniques to evaluate transcriptional, functional, and metabolic phenotypes as well as the $\mathrm{T}$ cell receptor repertoire, we investigated whether PD-1expressing $\mathrm{CD}^{+} \mathrm{T}$ cells from chronically inflamed tissue sites show signs of exhaustion or terminal differentiation or, rather, show increased effector function. We here demonstrate that, at the target site of human chronic inflammatory diseases, a specific subset of highly activated PD-1-expressing $\mathrm{CD} 8^{+} \mathrm{T}$ cells are induced, enriched for both an effector and tissue-resident memory (Trm) cell transcriptional profile. Furthermore, we show that this unique subset is locally clonally expanding and may therefore have detrimental effects in human organ-specific chronic inflammatory diseases. Together, these data may provide the rationale for investigation of therapeutic strategies targeting local PD1expressing $\mathrm{CD}^{+} \mathrm{T}$ cell subsets in chronic inflammation.

\section{Results}

Transcriptional profiling identifies a highly activated subset of PD$1^{+} C D 8^{+} T$ cells at the target site of inflammatory arthritis. As a model to investigate specific $\mathrm{CD}^{+} \mathrm{T}$ cell identity at the site of chronic 


\section{Table 1. Selected upregulated genes}

$\begin{array}{lcc}\text { Chemokines and receptors } & \text { IL-12-mediated signaling } & \text { Cell cycle } \\ \text { CCR1, CCL4 } & \text { IFNG } & \text { TYMS } \\ \text { CCR2, CCLL } & \text { GZMA } & \text { CENPE } \\ \text { CCR5, CCL23 } & \text { GZMB } & \text { E2F2 } \\ \text { CXCR6, CCL } 3 & & \text { CDCA5 } \\ & & \text { TOP2A }\end{array}$

Selected genes upregulated in PD-1+CD8 ${ }^{+} \mathrm{T}$ cells from SF are shown.

inflammation, we collected SF from JIA patients (SF-JIA), which is an exudate accumulating in the joint of patients during the active disease state. $\mathrm{CD} 8^{+} \mathrm{T}$ cells in SF-JIA were increased in frequency compared with those in the PB of JIA patients (PB-JIA), but not with the $\mathrm{PB}$ of healthy control children (PB-Ch) or the $\mathrm{PB}$ of healthy control adults (PB-HC) (Supplemental Figure 1A; supplemental material available online with this article; https://doi. org/10.1172/JCI96107DS1). In SF-JIA, effector memory CD8 ${ }^{+} \mathrm{T}$ cells were the predominant subset, followed by $\mathrm{CD} 8^{+}$terminally differentiated effector memory (CD8 ${ }^{+}$Ttemra) cells and by small fractions of central memory and naive $\mathrm{CD} 8^{+} \mathrm{T}$ cells (Supplemental Figure 1B), which is similar to what was previously described in RA patients (4). Of note, markers that further characterize the differentiation status of $\mathrm{CD} 8^{+} \mathrm{T}$ cells, such as $\mathrm{CD} 28, \mathrm{CD} 27$, and $\mathrm{CD} 127$, were comparable between PB-HC and PB-JIA and therefore are not age dependent (Supplemental Figure 2).

$\mathrm{PD}-1^{+} \mathrm{CD}^{+} \mathrm{T}$ cells were highly enriched in SF-JIA when compared with PB-JIA, PB-Ch, and PB-HC (Figure 1A), and this was true also for $\mathrm{PD}-1$ expression levels (mean fluorescence intensity [MFI]) on $\mathrm{CD}^{+} \mathrm{T}$ cells (data not shown). Similarly to both PB-JIA and PB-HC, $\mathrm{PD}-1^{+} \mathrm{CD} 8^{+} \mathrm{T}$ cells from $\mathrm{SF}$ were almost exclusively memory cells (i.e., $\mathrm{CD} 45 \mathrm{RO}^{+}$), while the only $\mathrm{CD} 45 \mathrm{RO}^{-} \mathrm{CD} 8^{+} \mathrm{T}$ cells present in $\mathrm{SF}$ were found within the PD-1- compartment (Figure 1B). However, a larger proportion of PD-1 cells were found to be $\mathrm{CD} 8^{+}$Ttemra cells compared with the PD-1+ fraction (24.4\% versus $9.2 \%$ ), meaning that, despite the different level of differentiation, the PD- $1^{+}$and PD-1 subsets in SF are both predominantly made by memory cells (Figure 1C).

To further investigate the phenotype of PD-1-expressing CD $8^{+}$ $\mathrm{T}$ cells enriched at the site of inflammation, whole-transcriptome sequencing analysis was performed on sorted $\mathrm{PD}-1^{+}$and $\mathrm{PD} 1^{-} \mathrm{CD} 8^{+}$ $\mathrm{T}$ cells from SF-JIA and PB-HC. As expected, the hierarchical clustering showed a cut-off separation between PB-HC and SF-JIA samples (Supplemental Figure 3). Principal component analysis (PCA) confirmed these data, additionally showing a better-defined segregation between PD-1 $1^{+}$and $\mathrm{PD}-1^{-} \mathrm{CD} 8^{+} \mathrm{T}$ cells in $\mathrm{SF}$ compared with $\mathrm{PD}^{+}$and $\mathrm{PD}^{-}$in $\mathrm{PB}$ (Figure 1D). Interestingly, a much higher number of differentially expressed genes between PD $-1^{+}$and PD-1 $\mathrm{CD} 8^{+} \mathrm{T}$ cells was found in SF-JIA (i.e., $n=436$ ) compared with PB$\mathrm{HC}$ (i.e., $n=29$; Figure 1E). Therefore, although these $\mathrm{CD} 8^{+} \mathrm{T}$ cells are derived from the same inflammatory environment and have a memory phenotype in common, $\mathrm{PD}-1$ expression seems to define a unique $\mathrm{CD}^{+} \mathrm{T}$ cell subset in SF-JIA.

K-mean analysis revealed a cluster of 173 genes that was selectively upregulated in the PD- $1^{+}$subset from SF-JIA when compared with PD-1 $1^{-}$cells from SF-JIA and PD- $1^{+}$and PD-1- cells from PB-HC (Figure 1F). Interestingly, upregulated genes in $\mathrm{PD}-1^{+} \mathrm{CD} 8^{+} \mathrm{T}$ cells from SF-JIA were significantly enriched in pathways associated with activated cells, such as cell-cycle regulation and chemokine and cytokine signaling as well as IL-12 signaling (Figure 1G). Selected genes upregulated in the PD-1+ $1^{+}$subset from SF are shown in Table 1 and include chemokine receptors and ligands (e.g., CCR1, CCR2, CCR5, CXCR6, CCL4, and CCL5), IL-12-induced effector molecules (i.e., IFNG, GZMA, GZMB), and proteins directly involved in the cell cycle (i.e., TYMS, E2F2, TOP2A). Differentially expressed genes between PD-1 $1^{+}$and PD-1 $1^{-}$cells in SF are shown in Supplemental Table 1. In Supplemental Figure 4, expression levels of individual genes are shown. Interestingly, gene expression of negative costimulatory markers typically elevated in exhausted $\mathrm{T}$ cells, such as LAG3, HAVCR2, CD160, and CD244, was not consistently higher in $\mathrm{PD}-1^{+} \mathrm{CD} 8^{+} \mathrm{T}$ cells from $\mathrm{SF}$ compared with the PD-1' subset (Figure 1H). A total of 179 genes, instead, was found to be downregulated in $\mathrm{PD}-1^{+}$versus $\mathrm{PD}-1^{-} \mathrm{CD} 8^{+} \mathrm{T}$ cells from SFJIA, including killer cell immunoglobulin-like receptors (KIRs) (Supplemental Figure 5, A and B). Downregulation of molecules with inhibitory functions confirmed the activated phenotype of the PD $-1^{+} \mathrm{CD} 8^{+} \mathrm{T}$ cell subset. Additionally, we ruled out that phenotypical and functional differences observed between PD-1 $1^{+}$and PD-1 $1^{-}$ $\mathrm{CD}^{+} \mathrm{T}$ cells from SF-JIA were driven by the memory phenotype; indeed, both proliferation (i.e., Ki67) and cytotoxicity (i.e., GzmB production) were increased in $\mathrm{CD} 45 \mathrm{RO}^{+} \mathrm{PD}-1^{+}$cells when compared with $\mathrm{CD} 45 \mathrm{RO}^{+} \mathrm{PD}-1^{-}$cells (Supplemental Figure 6), showing that the effector profile observed in PD-1+ ${ }^{+}$cells is not driven by the memory phenotype itself. These data show that PD-1-expressing cells enriched at the site of inflammatory arthritis are a specific subset of $\mathrm{CD} 8^{+} \mathrm{T}$ cells endowed with an activated phenotype.

$P D$-1-expressing $C D 8^{+} T$ cells from the target site of inflammatory arthritis are enriched for an "effector" and not an "exhaustion" profile. To investigate the possibility that $\mathrm{PD}-1$-expressing $\mathrm{CD} 8^{+} \mathrm{T}$ cells from SF-JIA are exhausted, we compared their gene expression profile with the known expression signature of exhausted cells using gene set enrichment analysis (GSEA) (17). We showed that the gene signature of previously described exhausted $\mathrm{CD} 8^{+} \mathrm{T}$ cells from HIV patients with progressive disease (18) was enriched neither in $\mathrm{PD}-1^{+}$nor $\mathrm{PD}-1^{-} \mathrm{CD} 8^{+} \mathrm{T}$ cells from SF, demonstrating that $\mathrm{PD}-1^{+} \mathrm{CD}^{+} \mathrm{T}$ cells from SF-JIA do not display an exhausted profile (Figure 2A). Instead, $\mathrm{PD}-1^{+} \mathrm{CD}^{+} \mathrm{T}$ cells (Figure 2B) had an expression profile that was enriched for signature effector $\mathrm{CD} 8^{+}$cell genes (19) and genes associated with cell proliferation (Figure 2C), compared with SF-derived PD-1-CD $8^{+} \mathrm{T}$ cells. Furthermore, T-bet and Blimp-1, transcription factors implicated in $\mathrm{CD} 8^{+} \mathrm{T}$ cell exhaustion (20-22), showed a similar expression level in the PD-1 $1^{+}$and PD-1subsets (data not shown), indicating that transcriptional regulators of exhausted cells are not relevant in this setting. These data, together with the elevated intracellular expression of the marker of cell proliferation Ki-67 (Figure 2D), strongly suggest that SF-derived $\mathrm{PD}-1^{+} \mathrm{CD} 8^{+} \mathrm{T}$ cells are not exhausted and proliferate in vivo.

Complementary analysis confirmed these data showing that genes upregulated in PD-1 $1^{+}$versus PD-1-CD ${ }^{+} \mathrm{T}$ cells in SF (Supplemental Figure 7A) or shared between PD-1+ ${ }^{+}$SF-JIA versus PD-1+ PB$\mathrm{HC}$ and PD-1+ $1^{+}$versus PD-1- $\mathrm{SF}-\mathrm{JIA}$ (Supplemental Figure 7B) were consistently enriched in pathways associated with effector cells.

Immune cell differentiation and function depend on the activation of specific metabolic pathways: quiescent $\mathrm{T}$ cells gen- 
A

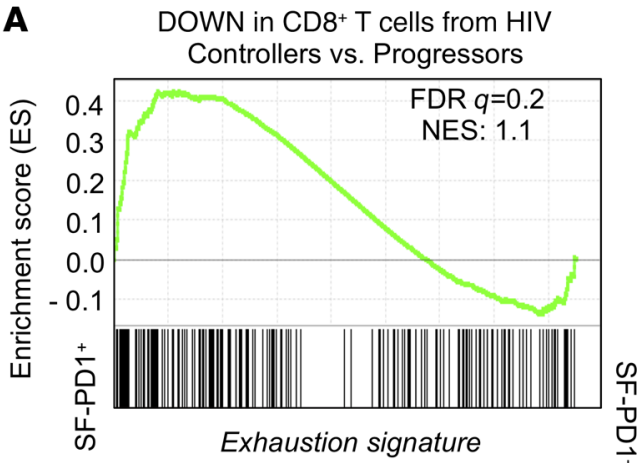

C

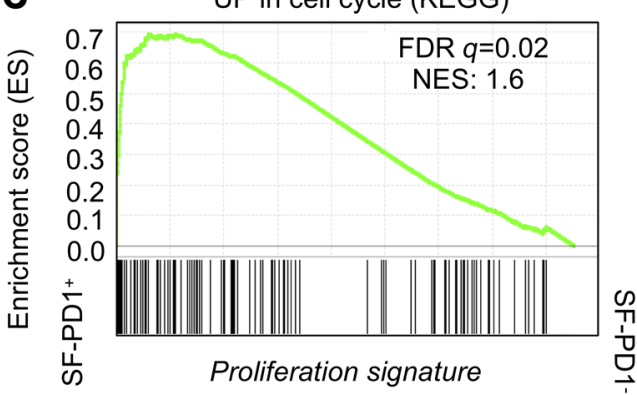

B

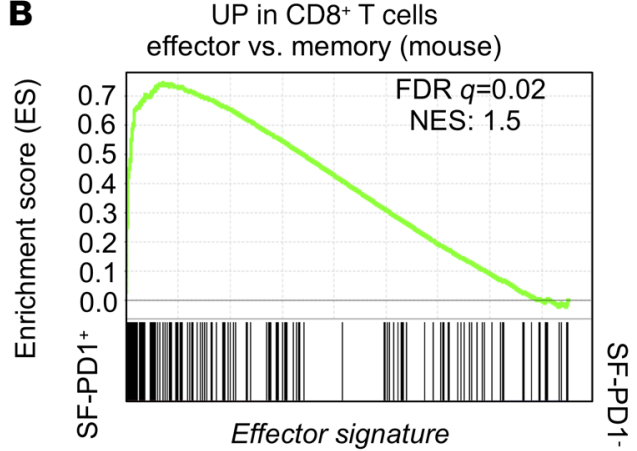

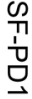

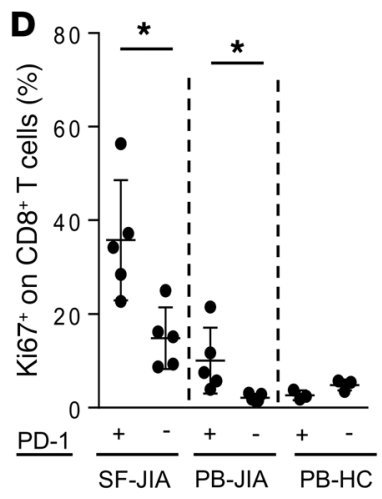

$\mathbf{F}$

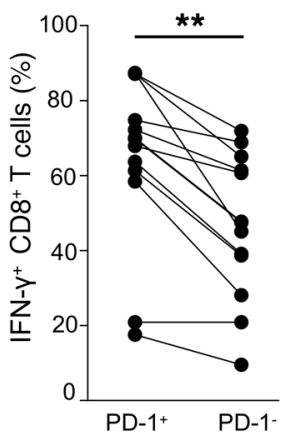

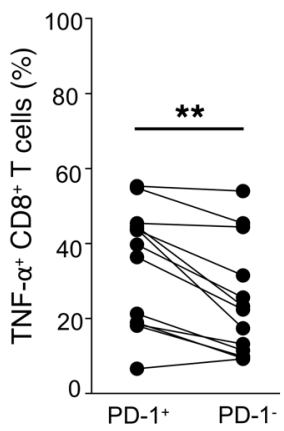

G

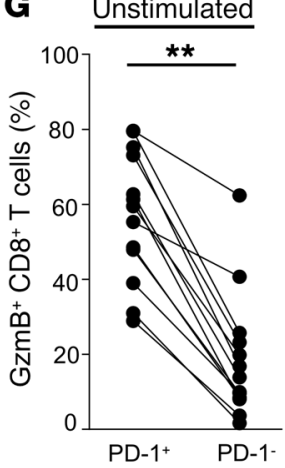

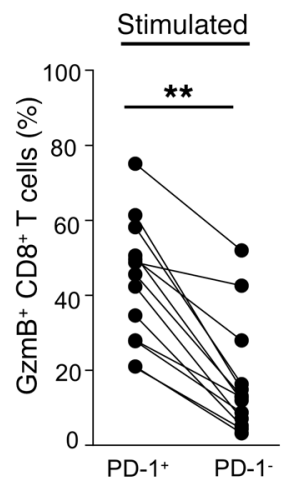

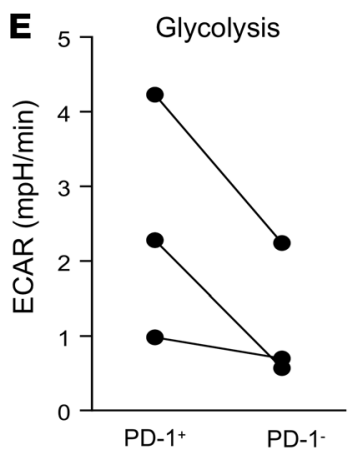

H
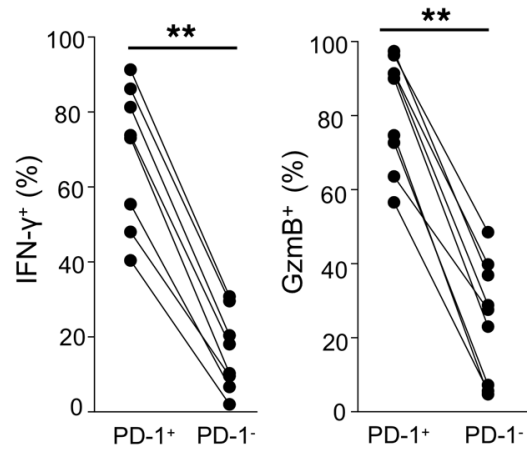

Figure 2. PD1-expressing CD8+ $T$ cells are effector, metabolically active, and not exhausted cells at the target site of inflammatory arthritis. (A) Enrichment of previously published gene signatures of $C D 8^{+} T$ cell exhaustion (described in ref. 18) was tested on PD-1 $1^{+}$vs. PD-1 $1^{-}$CD $8^{+} T$ cells from SF by GSEA. (B) Enrichment of previously published gene signatures of effector CD8 ${ }^{+}$T cells (described in ref. 19) was tested on PD-1 $1^{+}$vs. PD-1-CD8+ T cells from SF by GSEA. NES, normalized enrichment score. (C) Enrichment of genes linked to cell cycle (obtained from the KEGC database) was tested on PD-1 ${ }^{+}$Vs. PD-1-CD8 ${ }^{+} T$ cells from SF. (D) Assessment of cell proliferation was performed by Ki-67 staining on PD-1+ and PD-1-CD8 ${ }^{+}$T cells from SF-JIA and PB-JIA as well as PB of healthy donors ( $n=5$ per group). Data are shown as mean \pm SD. ${ }^{*} P<0.05$, paired Student's $t$ test. (E) The metabolic phenotype of PD-1 ${ }^{+}$and PD-1 $1^{-} C D 8^{+} T$ cells from SF was tested by XF technology (Seahorse Bioscience). Glycolysis was calculated as the difference between levels of ECAR upon exposure to glucose vs. exposure to the glycolysis inhibitor 2-DC. NS, paired Student's $t$ test. (F) The frequency of IFN- $\gamma$-producing (left panel) and TNF- $\alpha$-producing (right panel) $\mathrm{PD}-1^{+}$and $\mathrm{PD}-1^{-} \mathrm{CD} 8^{+}$T cells was tested upon in vitro PMA/ionomycin stimulation. ${ }^{*} P<0.01$, paired Student's $t$ test. (C) The cytotoxic potential of $\mathrm{PD}-1^{+}$and $\mathrm{PD}-1^{-} \mathrm{CD} 8^{+} \mathrm{T}$ cells was tested by assessing the frequency of GzmB-producing cells ex vivo (left panel) and upon in vitro PMA/ionomycin stimulation (right panel). ${ }^{*} P<0.01$, paired Student's $t$ test. $(\mathbf{H}) \mathrm{PD}-1^{-C D} 8^{+} \mathrm{T}$ cells were sorted from SF-JIA and plated in the presence of anti-CD3/CD28 stimuli (1:5 ratio). After 40-hour stimulation, intracellular levels of IFN- $\gamma$ (left panel) and GzmB (right panel) on PD-1+ and PD-1-CD8 ${ }^{+} T$ cells were measured. ${ }^{*} P<0.01$, paired Student's $t$ test SF-PD1 ${ }^{+}$, SF-derived PD1 ${ }^{+} \mathrm{CD}^{+} \mathrm{T}$ cells; SF-PD1-, SF-derived PD1-CD8 ${ }^{+} \mathrm{T}$ cells; DOWN: downregulated.

erate energy (i.e., ATP) primarily in their mitochondria via oxidative phosphorylation, while effector cells engage anaerobic glycolysis, converting glucose into lactate $(23,24)$. To further support the evidence that $\mathrm{PD}-1^{+} \mathrm{CD} 8^{+} \mathrm{T}$ cells from SF-JIA are not exhausted, we analyzed the level of glucose consumption in these cells by measuring the ex vivo extracellular acidification rate (ECAR) with extracellular flux (XF) technology (Seahorse Bioscience). In the exhaustion setting, PD-1 is known to regulate metabolism by inhibiting glycolysis (25). Consistent with the effector cell phenotype that we found in SF, PD- $1^{+} \mathrm{CD} 8^{+} \mathrm{T}$ cells showed increased glycolysis compared with the PD-1- subset from the same site (Figure 2E). 
A

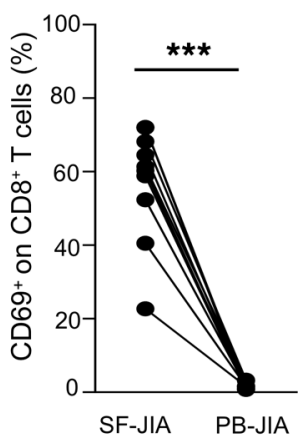

E
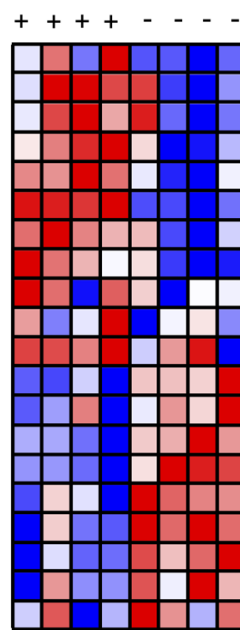

B

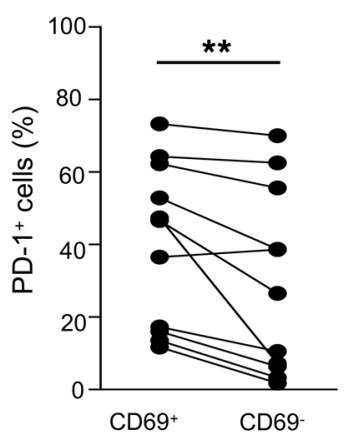

C UP in Trm vs. peripheral memory $\mathrm{CD}^{+} \mathrm{T}$ cells (mouse)

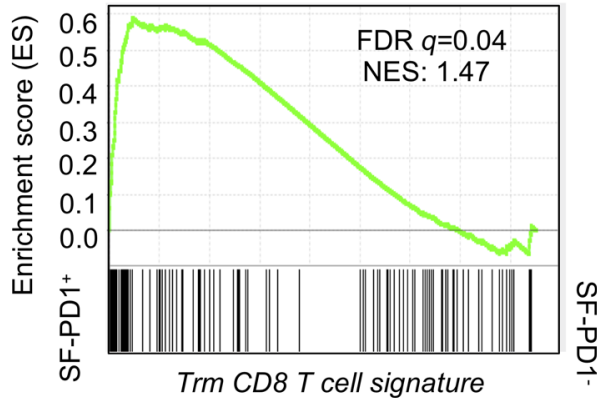

$\mathbf{F}$
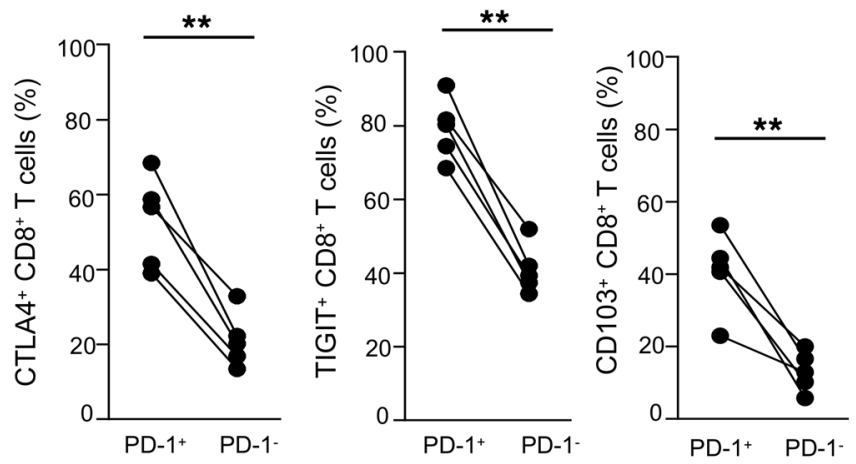

CXCL13

ITGA1

CXCR6

TTYH2

PDCD1

RGS1

CRTAM

CX3CR1

KCNK5

STK38

FAM65B

SELL

SOX13

PTGDS

TSPAN18

IL23R

row min

row max

PD-1

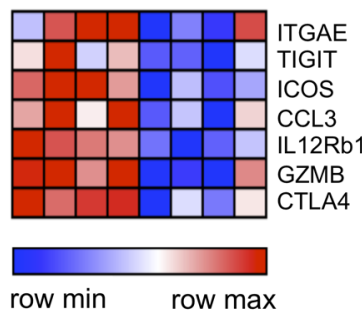

G

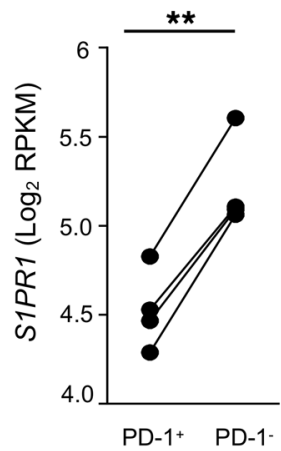

Figure 3. PD1-expressing CD8 ${ }^{+} T$ cells display a Trm profile at the target sites of human inflammatory arthritis. (A) Frequency of CD69+ $C D 8^{+} T$ cells in SF-JIA compared with PB-JIA is shown. ${ }^{* *} P<0.0001$, paired Student's $t$ test. (B) PD-1 expression on Trm (CD69+) compared with recirculating (CD69-) CD8 ${ }^{+} T$ cells is shown. ${ }^{*} P<0.01$, paired Student's $t$ test. (C) Enrichment of previously published gene signatures of Trm CD8 ${ }^{+} T$ cells (described in ref. 29) was tested on PD-1+ vs. PD-1-CD8+ T cells from SF by GSEA. (D) Heatmap shows color-coded gene expression levels of selected genes upregulated in mouse-derived Trm cells (29) in PD-1+ and PD-1-CD8+ $T$ cells from SF. (E) Heatmap shows color-coded gene expression levels of selected signature genes of human-derived Trm cells (32) in PD-1+ and PD-1-CD8 ${ }^{+}$T cells from SF. (F) The frequency of CTLA-4 $4^{+}$, TIGIT+, and CD103+ cells was measured on PD-1+ and PD-1-CD8 ${ }^{+}$T cells from SF. ${ }^{*} P<0.01$, paired Student's $t$ test. (C) Expression of S1PR1 at mRNA level on PD-1 ${ }^{+}$and PD-1 ${ }^{-}$CD8 ${ }^{+}$T cells from SF. ${ }^{*} P<0.01$, paired Student's $t$ test.

We further assessed $\mathrm{PD}-1^{+} \mathrm{CD} 8^{+} \mathrm{T}$ cell properties by performing a short nonspecific stimulation with PMA/ionomycin. This showed an increased expression of proinflammatory (i.e., IFN- $\gamma$ and TNF- $\alpha$ ) cytokines by PD-1 $1^{+}$compared with PD-1 $1^{-} \mathrm{CD}^{+}$ $\mathrm{T}$ cells (Figure $2 \mathrm{~F}$ ). Furthermore, $\mathrm{PD}-\mathrm{1}^{+}$cells were found to produce elevated levels of the cytotoxic enzyme GzmB both ex vivo and upon in vitro stimulation (Figure $2 \mathrm{G}$ ). Finally, PD-1 $\mathrm{CD} 8^{+}$ $\mathrm{T}$ cells from SF-JIA were sorted and plated in the presence of anti-CD3/CD28 stimuli. After 40-hour TCR stimulation, $42.8 \% \pm 25.7 \%$ PD $-1^{-}$cells turned PD $1^{+}$, while the leftover cells remained negative for PD-1 (data not shown). Interestingly, ex-PD-1 $1^{-}$cells that turned PD-1+ ${ }^{+}$showed an effector phenotype (i.e., elevated production of IFN- $\gamma$ and GzmB) compared with cells that remained negative for PD-1 (Figure $2 \mathrm{H}$ ). These data indicate that $\mathrm{PD}-1^{+} \mathrm{CD} 8^{+} \mathrm{T}$ cells are induced by $\mathrm{TCR}$ stimulation and have a superior proinflammatory and cytotoxic potential compared with their PD-1 counterparts.
Furthermore, we attempted to define whether PD-1 signaling was functional in SF. The PD-1 pathway was triggered by coculturing SF-derived PD-1+ $1^{+}$with anti-CD3/CD28 beads in the presence of the anti-PD-1 agonist (Supplemental Figure 8). Both GzmB and IFN- $\gamma$ production were reduced upon PD-1 ligation, indicating that effector PD- $1^{+} \mathrm{CD} 8^{+} \mathrm{T}$ cells induced at the site of chronic inflammation of JIA can, at least in part, respond to PD-1 triggering ex vivo.

Taken together, these findings indicate that PD-1-expressing $\mathrm{CD}^{+} \mathrm{T}$ cells are endowed with typical features of effector, but not exhausted, cells at the transcriptional, metabolic, and functional levels.

$P D$-1-expressing $C D 8^{+} T$ cells at the target site of inflammation of different human chronic inflammatory diseases display a Trm profile. Trm cells have been recently described as a resting memory cell subset expressing CD69, stably residing in tissues, with a critical role in local immunosurveillance (26-28). Although the SF-derived cells by definition are not tissue resident - they are isolated from 
A

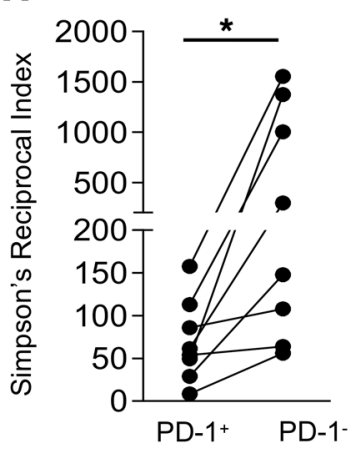

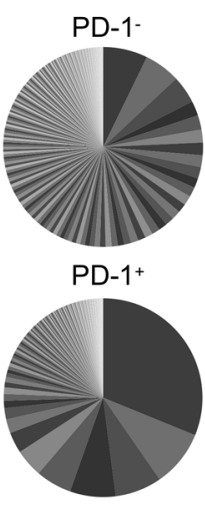

B

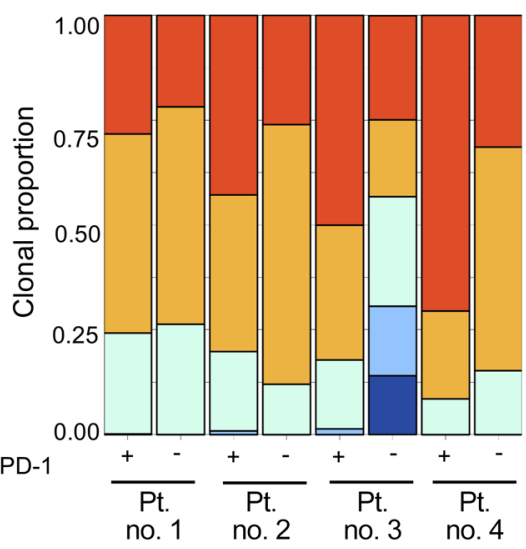

Top $\mathrm{N}$ clones

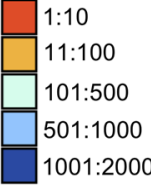

C

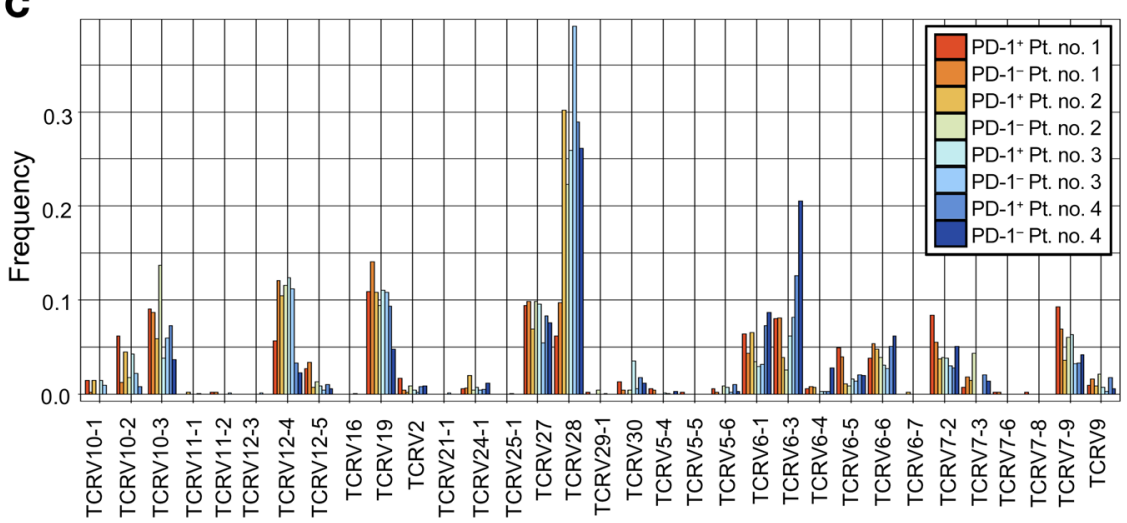

D
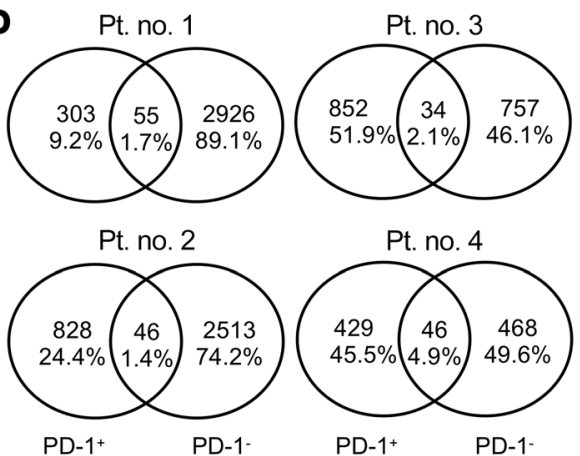
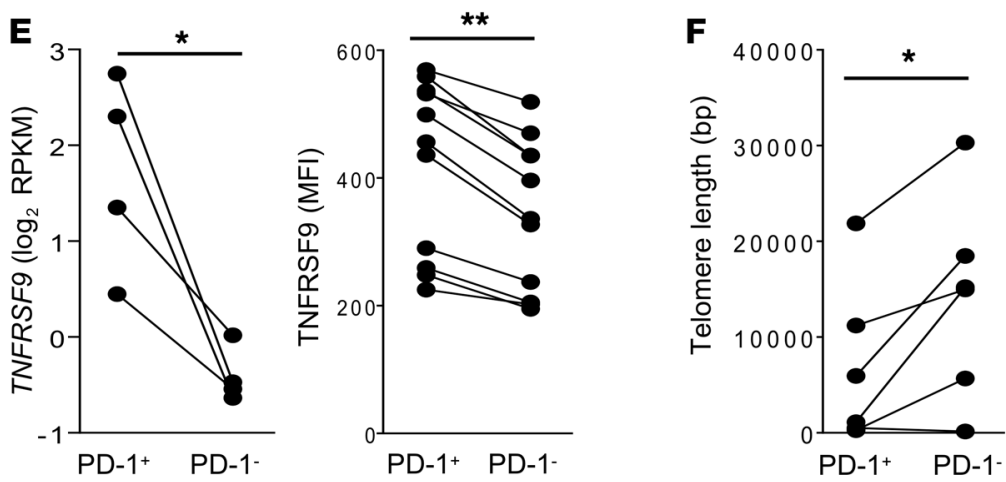

G

Pt. no. 5

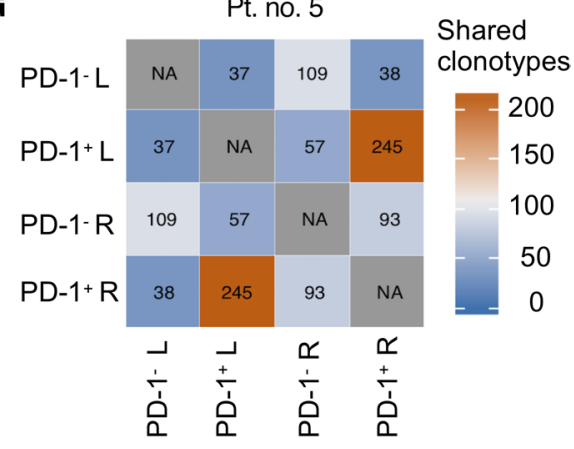

Figure 4. PD1-expressing CD8 ${ }^{+} \mathrm{T}$ cells are a unique subset undergoing local clonal expansion at the target site of inflammatory arthritis. Next-generation TCRBV CDR3 sequencing was performed on PD-1 $1^{+}$and PD-1-CD8 ${ }^{+}$T cells from SF. (A) Simpson's reciprocal index was assessed as indicator of TCR diversity (left panel). ${ }^{*} P<0.05$, paired Student's $t$ test. Representative pie charts show the distribution of unique clones. (B) Analysis of the clonal proportion showing prevalence of the top clones in PD-1+ and PD-1-CD8 ${ }^{+}$T cell subsets from SF. (C) Usage of the TCR-V $\beta$ chain was assessed in both PD-1+ and PD-1-CD8+ $T$ cells from SF. (D) Numbers of unique clones and sequences overlapping between PD-1+ and PD-1-CD8+ $T$ cells are shown for patients 1 through 4 by Venn diagrams. (E) Expression of the surrogate marker of antigen specificity TNFRSF9 (i.e., CD137) was assessed in PD-1 ${ }^{+}$and PD-1-CD8 ${ }^{+} T$ cells from SF both at mRNA (left panel) and protein (right panel) levels. ${ }^{*} P<0.05 ;{ }^{*} P<0.01$, paired Student's $t$ test. (F) Telomere length was tested on PD-1 ${ }^{+}$and PD-1-CD8 ${ }^{+} T$ cells from SF. ${ }^{*} P<0.05$, paired Student's $t$ test. (G) In 1 patient, PD-1+ and PD-1-CD8 ${ }^{+} T$ cells from 2 joints were sorted and TCR sequencing was performed. The number of clones shared between PD-1+ and PD-1-CD8 ${ }^{+}$T cells coming from the 2 joints are indicated in each square. R, right; $L$, left.

exudate and not from tissue - we were wondering whether they may share some characteristics, especially since PD-1 and other negative costimulatory markers (such as CTLA-4, ICOS, and TIGIT) have been shown to be upregulated on Trm cells in mice (29) and humans (30).

In our setting, $\mathrm{CD} 69^{+} \mathrm{CD} 8^{+} \mathrm{T}$ cells were present at a high frequency in SF compared with PB of the same patients (Figure 3A), and PD-1 expression was higher on total $\mathrm{CD} 69^{+}$compared with CD69- ${ }^{-} D 8^{+} \mathrm{T}$ cells in SF (Figure 3B). Moreover, $\mathrm{CD} 69^{+} \mathrm{CD} 103^{+}$ and $\mathrm{CD} 69^{+} \mathrm{CD} 103^{-} \mathrm{CD} 8^{+} \mathrm{T}$ cells, associated with 2 distinct subsets of $\mathrm{CD}^{+} \mathrm{Trm}$ cells (31), were both present in SF, with a prevalence of the $\mathrm{CD} 69^{+} \mathrm{CD} 103^{-}$fraction (Supplemental Figure 9A). Interestingly, barely any $\mathrm{CD} 103^{+} \mathrm{CD} 8^{+} \mathrm{T}$ cells were present in the $\mathrm{PD}-1^{-}$ subset (Supplemental Figure 9B). 
Table 2. Patient characteristics

\begin{tabular}{|c|c|c|c|c|c|c|}
\hline & $\begin{array}{c}\text { Median age in years } \\
\text { (IQR, 25th-75th percentile) }\end{array}$ & $\begin{array}{c}\text { Sex } \\
(M / F)\end{array}$ & $\begin{array}{c}\text { Type of JIA } \\
\text { (Oligoarticular/polyarticular) }\end{array}$ & $\begin{array}{c}\text { ANA } \\
\text { positivity }\end{array}$ & $\begin{array}{l}\text { Presence } \\
\text { of RF }\end{array}$ & Treatment \\
\hline JIA patients $(n=52)$ & $11,6(8-15,6)$ & $26 / 26$ & $40 / 12$ & $n=26$ & $n=2$ & $\begin{array}{c}n=19: \text { MTX; } \\
n=\text { 3: low-dose prednisone; } \\
n=6 \text { : anti-TNF monoclonal antibody; } \\
n=1: \text { MMF; } \\
n=23: \text { untreated }\end{array}$ \\
\hline
\end{tabular}

IQR, interquartile range; ANA, antinuclear antibodies; RF, rheumatoid factor; MTX, methotrexate; MMF, mycophenolate mofetil.

GSEA showed that PD $-1^{+} \mathrm{CD} 8^{+} \mathrm{T}$ cells, but not PD-1 cells, from SF-JIA were enriched with the signature of Trm cells (29) (Figure 3C). Moreover, increased expression levels of signature genes of Trm cells in mice (29) (Figure 3D) and differential expression of the core transcriptional signature of human Trm cells (32) (Figure $3 \mathrm{E}$ ) were found in SF-derived PD- $\mathbf{1}^{+}$cells. This was confirmed by the increased protein expression of CTLA-4, TIGIT, and CD103 on $\mathrm{PD}-\mathrm{1}^{+} \mathrm{CD}^{+} \mathrm{T}$ cells (Figure $3 \mathrm{~F}$ ) as well as the decreased expression of S1PR1 (encoding for sphingosine 1-phosphate receptor [S1P1], whose downregulation is required for the establishment of resident $\mathrm{CD} 8^{+} \mathrm{T}$ cells; ref. 33 ) (Figure $3 \mathrm{G}$ ). We also found that the signature of $\mathrm{PD}-1^{+}$cells from SF was partially shared with the one from human tumor-specific $\mathrm{CD}^{+}$tumor-infiltrating lymphocytes (TIL) (34), with a trend toward enrichment with genes upregulated in CD8 ${ }^{+}$TIL from melanoma patients and no enrichment in either of the 2 subsets for downregulated genes (Supplemental Figure 10). These data demonstrate an overlapping profile between PD-1-expressing $\mathrm{CD}^{+} \mathrm{T}$ cells in SF and Trm cells, suggesting that inflammation may be one of the drivers of the Trmassociated phenotype. Furthermore, expression levels of Hobit, the master regulator of Trm cell development in mice (35), were similar between SF-derived PD- $1^{+}$and PD- $1^{-}$cells and lower when compared with $\mathrm{PB}$-derived $\mathrm{CD}^{+} \mathrm{T}$ cells and NKT cells from $\mathrm{HC}$ (data not shown), indicating that Hobit is not a transcription factor selective for SF-derived PD- $1^{+} \mathrm{CD} 8^{+} \mathrm{T}$ cells in humans.

We then determined whether similar features were evident in tissues obtained from patients with chronic inflammatory diseases, such as AD and IBD. Immunohistochemistry on histological sections of the lesional skin of 3 patients with $\mathrm{AD}$ showed that a large fraction of $\mathrm{CD}^{+} \mathrm{T}$ cells present in the dermis coexpressed PD-1 (Supplemental Figure 11A). Serial sections from the same AD patients were stained for the Trm cell marker CD69, showing its ubiquitous expression in lesional infiltrates (Supplemental Figure 11A). Approximately half of Trm cells present in the dermis coexpressed PD-1. Sections of nonlesional skin were stained as well, but very few $\mathrm{CD} 8^{+}$cells were present (Supplemental Figure 12). Similar results were also obtained from the site of inflammation of IBD patients with active disease ( $n=3$ Crohn's disease and $n=$ 1 ulcerative colitis), i.e., the colonic mucosa, where, in the macroscopically inflamed gut mucosa, $\mathrm{PD}-1^{+} \mathrm{CD} 8^{+} \mathrm{T}$ cells were elevated compared with $\mathrm{PB}-\mathrm{HC}$ and almost exclusively expressed by Trm $\mathrm{CD} 8 \alpha^{+} \mathrm{CD} 4^{-} \mathrm{T}$ cells (i.e., CD69 ${ }^{+}$cells) and not by recirculating (i.e., CD69- cells) $\mathrm{CD}^{+} \mathrm{T}$ cells (Supplemental Figure 11B).

Overall, these data show that $\mathrm{PD}-1^{+} \mathrm{CD}^{+} \mathrm{T}$ cells are present and enriched in both tissue and exudate of human chronic inflammatory diseases and display a Trm-like profile, suggesting that inflammation might be a driver for the local development or expansion of these cells.

$P D$-1-expressing $C D 8^{+} T$ cells from the target site of inflammatory arthritis represent a specific clonally expanded population. In the absence of a known autoantigen in JIA, we asked whether the inflammation-associated enrichment in $\mathrm{PD}^{+} \mathrm{CD}^{+} \mathrm{T}$ cells was due to a random influx of $\mathrm{PD} 1^{+} \mathrm{CD} 8^{+} \mathrm{T}$ cells or to a specific clonal expansion of this population at this site.

Next-generation TCRBV CDR3 sequencing was performed on PD $-1^{+}$and PD $-1^{-} \mathrm{CD}^{+} \mathrm{T}$ cells from SF. The analysis of amino acid sequences showed that the top $80 \%$ TCR repertoire of $\mathrm{PD}-1^{+} \mathrm{CD} 8^{+}$ $\mathrm{T}$ cells from SF-JIA was less diverse compared with that of PD-1 cells (Figure 4A). For instance, in patient no. 4 (Figure $4 \mathrm{~A}$ ), $52 \%$ of the TCR diversity is explained by 28 clones in the PD-1- fraction, but only 4 clones in the PD- $1^{+}$fraction. This was confirmed by analysis of the clonal proportion, showing that the top 10 most expanded clones account for $25 \%$ to $70 \%$ of the repertoire of $\mathrm{PD}-1^{+}$cells and for $20 \%$ to $25 \%$ of that of $\mathrm{PD}-1^{-}$cells (Figure $4 \mathrm{~B}$ ). Additionally, we found that the TCRV28 chain is preferentially used by all CD8 ${ }^{+} \mathrm{T}$ cells from SF, with no specific skewing of the $\mathrm{V}$ repertoire in $\mathrm{PD}-\mathrm{1}^{+}$ $\mathrm{CD}^{+} \mathrm{T}$ cells (Figure $4 \mathrm{C}$ ). When we tested the presence of shared unique TCR clones between PD $-1^{+}$and PD $-1^{-}$cells, we surprisingly found that their frequency was extremely low compared with the total number of identified clones (Venn diagrams in Figure 4D), suggesting that $\mathrm{PD}-1^{+} \mathrm{CD} 8^{+} \mathrm{T}$ cells present in $\mathrm{SF}$ represent a specific population of cells, distinct from $\mathrm{PD}-1^{-}$cells.

To further confirm that $\mathrm{PD}-1^{+} \mathrm{CD} 8^{+} \mathrm{T}$ cells are clonally expanded, we tested the expression of TNFRSF9 (i.e., CD137), described as regulating $\mathrm{CD}^{+} \mathrm{T}$ cell clonal expansion and associated with recent TCR-triggered activation (36) as well as the length of telomeres, known to shorten along with cell division and differentiation (37). $\mathrm{PD}-1^{+} \mathrm{CD} 8^{+} \mathrm{T}$ cells showed higher mRNA expression levels of TNFRSF9, and despite the overall low detection level, higher intensity was evident in $\mathrm{PD}-1^{+}$compared with $\mathrm{PD}-1^{-}$cells at a protein level (Figure 4E). Additionally, telomere length analysis showed shorter telomeres of $\mathrm{PD}-1^{+}$compared with $\mathrm{PD}-1^{-} \mathrm{CD} 8^{+} \mathrm{T}$ cells from SF in 3 out of 4 samples (Figure $4 \mathrm{~F}$ ). In 1 patient, the telomere had such a short length already that no differences between the PD $-1^{+}$and $\mathrm{PD}-1^{-}$subsets could be detected (Figure $4 \mathrm{~F}$ ).

In 1 JIA patient (i.e., no. 5), we could obtain PD- $1^{+}$and PD-1 $1^{-}$ $\mathrm{CD}^{+} \mathrm{T}$ cells from 2 different inflamed joints involved during active disease. A clear increased overlap of TCR sequences between joints was found in PD-1 ${ }^{+}$but not PD-1- cells ( 245 vs. 109 respectively; Figure $4 \mathrm{G}$ ), indicating that the expansion occurring 
at different sites of inflammation in the $\mathrm{PD}-1^{+}$subset may be driven by common antigen or antigens.

Together, these data show that PD-1-expressing $\mathrm{CD}^{+} \mathrm{T}$ cells represent a distinct population of cells undergoing clonal expansion, possibly toward specific antigen or antigens selectively at the target sites of human inflammatory arthritis.

\section{Discussion}

$\mathrm{CD}^{+} \mathrm{T}$ cells localizing at the target site of chronically inflamed tissues undergo local differentiation, which may be driven and influenced by different factors, such as the tissue inflammatory state and the type of antigen or antigens. To date, little is known about the functional specialization that $\mathrm{CD} 8^{+} \mathrm{T}$ cells develop at the target sites of inflammation, and consequently, it is yet undetermined whether standard or experimental therapies can reshape or even resolve the inflammatory responses occurring at these sites. Elucidating these mechanisms might open new therapeutic avenues for clinical application.

In cancer and infectious diseases, also characterized by a state of chronic stimulation, $\mathrm{CD}^{+} \mathrm{T}$ cells undergo a well-described tumor or viral antigen-driven process of differentiation characterized by PD-1 upregulation and progressive loss of effector properties, described as exhaustion $(11,12)$, which can be efficiently rescued by inhibiting the PD-1/PD-L1 pathway (13-15). PD-1 is not the sole marker of exhausted cells, and enrichment of PD- $1^{+} \mathrm{T}$ cells does not per se mean "exhaustion." Indeed, 2 studies showed that the transcriptional signature reflecting $\mathrm{CD}^{+}$(but not $\mathrm{CD} 4^{+}$) $\mathrm{T}$ cell exhaustion enables the prediction of a better prognosis in individuals with chronic inflammatory diseases $(38,39)$. However, recent studies suggest that it may not be a pure loss of function, but more a sign of functional adaptation to the chronically inflamed milieu (11, 40). In this study, the role of PD-1-expressing $\mathrm{CD}^{+} \mathrm{T}$ cells from the target site of human chronic inflammatory diseases was dissected to explore whether these cells show signs of exhaustion or rather undergo a site-specific adaptation.

PD $-1^{+} \mathrm{CD}^{+} \mathrm{T}$ cells from SF-JIA clearly showed upregulation of pathways associated with effector but not exhausted phenotype, which was confirmed by GSEA and by the elevated proliferative capacity of $\mathrm{PD}-1^{+} \mathrm{CD} 8^{+} \mathrm{T}$ cells from $\mathrm{SF}$. Moreover, $\mathrm{PD}-1^{+} \mathrm{CD} 8^{+} \mathrm{T}$ cells from SF did not upregulate the whole spectrum of negative costimulatory markers that are typically enriched in exhausted $\mathrm{CD}^{+} \mathrm{T}$ cells (41). Additionally, they showed increased usage of the glycolytic pathway, which is required to meet the increased bioenergetic demands occurring in effectors but not exhausted $\mathrm{CD}^{+} \mathrm{T}$ cells (25). This finding, together with the evidence of a proinflammatory and cytotoxic phenotype, rules out the hypothesis that PD-1-expressing CD8 ${ }^{+} \mathrm{T}$ cells are exhausted in this context of chronic inflammation, as instead described in cancer and chronic viral infections (11). Local expansion of $\mathrm{PD}-1^{+} \mathrm{CD} 8^{+} \mathrm{T}$ cells is most likely driven by TCR triggering, which promoted PD-1 expression in SF-derived PD1-negative CD8 ${ }^{+} \mathrm{T}$ cells and also induced their effector profile. Although local $\mathrm{PD}-1^{+} \mathrm{CD} 8^{+} \mathrm{T}$ cell expansion may additionally be driven by cytokines promoting homeostatic proliferation (i.e., IL-7 or IL-15), we found only very low levels of these cytokines present in SF (data not shown).

PD-1 is a well-known marker of activation (42), and it has been shown to identify a population of oligoclonal $\mathrm{CD}^{+} \mathrm{T}$ cells endowed with tumor-specific effector properties in human melanoma metastasis (43). A few reports also show a positive correlation between PD- 1 and Ki- 67 in the periphery of virally infected macaques and humans $(44,45)$. Interestingly, chemokines such as CCL3 and CCL4, which are upregulated in PD-1-expressing $\mathrm{CD}^{+} \mathrm{T}$ cells from $\mathrm{SF}$, are known to be highly released by effector HIV-specific cells from HIV long-term nonprogressors (symptom-free patients who don't require antiretroviral therapy) (46). Therefore, PD-1, rather than being a marker of exhaustion or activation, seems to define a subset of antigen-experienced cells whose functional properties are influenced by the location and determined by the environment they are exposed to. This was supported by the finding that PD-1 expression was found elevated on $\mathrm{CD}^{+} \mathrm{T}$ cells localized at the target sites of different chronic inflammatory diseases, such as the synovium of JIA patients, the inflamed skin of AD patients, and the gut of patients with IBD. Confirming previous reports $(11,40,47)$, our data indicate that, at the target site of chronic inflammatory diseases, an exhausted phenotype does not mean complete loss of function, but rather functional adaptation and development of expansion capacity and possible memory features. In this context, it would be interesting to explore whether the DNA methylation program acquired along with the development of the exhaustion profile in tumorinfiltrating PD- ${ }^{\text {hi }} C D 8^{+} \mathrm{T}$ cells (48) is shared by locally expanding $\mathrm{PD}-1$-expressing $\mathrm{CD}^{+} \mathrm{T}$ cells in chronic inflammatory diseases. Although it is certainly possible that within the PD-1 population there are some exhausted cells, our data show that the PD-1 subset seems to be enriched for cells with an effector/proinflammatory phenotype that also has low numbers of CD8 ${ }^{+}$Ttemra cells. In addition, the high percentage of $\mathrm{PD}-1^{+} \mathrm{CD} 8^{+} \mathrm{T}$ cells expressing GzmB, TNF- $\alpha$, and IFN- $\gamma$ suggests that the PD $-1^{+} \mathrm{CD} 8^{+} \mathrm{T}$ cell subset in SF seems to be a relatively homogeneous population of locally accumulating effectors.

To assess whether PD-1 expression is only driven by the inflammatory milieu or depends on an antigen-driven component as well, we examined SF-derived PD- $1^{+}$and $\mathrm{PD}-1^{-} \mathrm{CD} 8^{+} \mathrm{T}$ cell clonality. $\mathrm{PD}-1^{+} \mathrm{CD} 8^{+} \mathrm{T}$ cells displayed a clonal TCR compared with the diverse PD-1 ${ }^{-}$counterpart from the same site, supporting the idea that this subset is driven by antigen specificity, despite the fact that no specific restriction of the TCRBV segment is observed. The evidence that few clones were shared between $\mathrm{PD}-1^{+}$and PD-1 ${ }^{-}$cells suggests that both cell subsets might only in part derive from common progenitors. Therefore, it is possible that $\mathrm{CD}^{+} \mathrm{T}$ cells in SF originate from clones present in the periphery that have specifically expanded in the synovium. Indirect evidence was provided by the increased expression of a surrogate marker of antigen-specific CD8 ${ }^{+}$T cells (i.e., TNFRSF9) and by the shortened telomere length, indicating a possible local clonal expansion toward cognate antigen or antigens at the site of inflammation. This hypothesis was supported by the evidence that, in the PD- $1^{+}$ compartment only, different sites of inflammation within the same patient displayed elevated TCR sequence overlap. This is in line with data in type 1 diabetes showing that self-reactive cells with the highest self-antigen affinity express the most PD-1 (49) and that gut-derived natural intraepithelial cells expressing PD-1 include strongly self-reactive clones and are restricted by classical major histocompatibility complex molecules (50). 
PD-1 expression was found elevated especially on $\mathrm{CD} 69^{+} \mathrm{CD} 8^{+}$ T cells. Growing literature has described CD69+ $\mathrm{T}$ cells localized in tissues as Trm cells, i.e., a subset of experienced $\mathrm{T}$ cells stably residing in tissues and providing local protection upon reexposure to pathogens $(51,52)$. Features of Trm cells, such as transcriptional profile $(29,30,32)$, partial overlap with tumor-derived $\mathrm{CD}^{+}$ TIL, expression of typical surface (retention) markers (i.e., CD69 and CD103), downregulation of S1PR1 (33), and upregulation of specific negative costimulatory markers as well as the cytotoxic enzyme GzmB $(29,30)$, could be found in PD-1-expressing CD8 ${ }^{+}$ $\mathrm{T}$ cells enriched in the SF-JIA. Our data indicate that local inflammation drives the development of Trm-like PD-1-expressing CD ${ }^{+}$ $\mathrm{T}$ cells. The cells we describe in this paper are localized in the SF; however, PD-1-expressing T cells (19) and CD8 ${ }^{+}$Trm cells (53) have been previously described in the synovial tissue of patients with RA. Therefore, it is possible that immune cells present in SF actually originate from the synovial tissue infiltrate and are pushed out in the fluid exudate. This locally adapted cell subset is endowed with a constitutively proinflammatory/cytotoxic profile and lies in a functional reactivated effector state. However, it is debatable whether $\mathrm{PD}-1$-expressing $\mathrm{CD}^{+} \mathrm{T}$ cells represent the activated form of Trmlike cells or rather a state of differentiation of $\mathrm{CD} 8^{+} \mathrm{T}$ cells driven by the inflammatory environment. Moreover, it would be interesting to observe whether this subset is still present in noninflammatory conditions and whether Trm-like PD-1-expressing CD8 ${ }^{+}$ $\mathrm{T}$ cells are indeed enriched in inflamed versus noninflamed tissues, reinforcing the evidence of their potential detrimental role in chronic inflammatory diseases. This hypothesis is supported by the observation that, in human skin, CD103 ${ }^{+}$Trm cells (in which PD-1 expression was found enriched) represent the subset with more pronounced effector functions compared with $\mathrm{CD} 103^{-}$Trm cells (31).

Finally, the questions arise as to why the $\mathrm{CD} 8^{+} \mathrm{T}$ cells are not kept in check by the high expression of PD-1 and whether PD-1 can still regulate $\mathrm{CD} 8^{+} \mathrm{T}$ cell functionality and/or proliferative capacity. The ligand of PD-1 (i.e., PD-L1) is expressed by antigenpresenting cells (APC) in SF (16) and the PD-1 signaling on $\mathrm{CD}^{+} \mathrm{T}$ cells appears to be, at least partially, functional ex vivo; however, the soluble form of PD-1 (sPD-1) is present at high levels at this site (54), thus counteracting PD-1-mediated suppression by blocking interaction with APC, which explains why this subset of effector cells cannot be suppressed at the site of inflammation. We believe PD-1 is a bystander marker of a subset of locally expanding clonal cells that, despite upregulating inhibitory markers (such as PD-1, LAG-3, CTLA-4, TIGIT), cannot be properly halted due to insufficient activity of inhibitory signaling. PD-1 signaling leads to downregulation of PI3K activation and subsequent reduced activation of Akt (55). Interestingly, Akt has been shown to be hyperphosphorylated in $\mathrm{CD}^{+} \mathrm{T}$ cells derived from SF (8), indicating that PD-1 signaling is not sufficient to downregulate the PI3K-Akt axis in these cells. It may even be possible that PD-1 signaling prevents the terminal differentiation and death of these cells, as recently shown in a mouse model of chronic viral infection, where the genetic absence of PD-1 led to the accumulation of more cytotoxic but terminally differentiated CD8 ${ }^{+} \mathrm{T}$ cells (56).

Using a variety of techniques, in this study, we have shown that PD-1-expressing $\mathrm{CD}^{+} \mathrm{T}$ cells enriched at the site of autoimmune inflammation are not exhausted but rather are antigen- experienced cells, have undergone tissue-instructed differentiation and clonal expansion, and are actively proliferating toward a cognate antigen, likely a self-antigen. A lot of research is currently directed toward PD-1 agonists as a novel treatment for chronic inflammatory diseases $(16,57,58)$. Halting migration to the site of inflammation or local depletion of resident effector cells showing tissue-specific harmful potential might have additional substantial therapeutic implications in chronic inflammatory diseases.

\section{Methods}

Patient characteristics. Patients with JIA were enrolled by the Paediatric Rheumatology Department at University Medical Center Utrecht. Clinical features of patients enrolled in this study are shown in Table 2. A total of 52 JIA patients were included in this study, 40 with oligoarticular JIA and 12 with polyarticular JIA, according to the revised criteria for JIA (59). Biological samples were collected, isolated, and stored in liquid nitrogen, then retrospectively selected based on inclusion criteria (age $\leq 18$, affected by either oligo- or polyarticular JIA) and exclusion criteria (presence of systemic and concurrent infectious diseases). The average age of the patient population was 11.7 years (range 2.5-23.8 years), and the disease duration at the time of inclusion was 5.8 years (range 0.5-19.5 years). SF was obtained from patients with active disease undergoing therapeutic joint aspiration. Paired blood and joint aspirate samples were collected from 16 patients. PB from adult healthy volunteers (HC, $n=33$ ) was obtained from the Mini Donor Service at University Medical Center Utrecht. PB from 17 healthy children was obtained from a cohort of control subjects for a case-control clinical study. Adult patients $(n=3)$ affected by $\mathrm{AD}$ underwent skin biopsies of lesional and nonlesional skin. Adult patients affected by active Crohn's disease $(n=3)$ or ulcerative colitis $(n=1)$ underwent endoscopy for surveillance, and 4 biopsies were taken from macroscopically inflamed colonic mucosa.

Cell isolation. SF mononuclear cells (SFMC) were incubated with Hyaluronidase (Sigma-Aldrich) for 30 minutes at $37^{\circ} \mathrm{C}$. SFMC and PB mononuclear cells (PBMC) were isolated using Ficoll Isopaque density gradient centrifugation (GE Healthcare Bio-Sciences, $\mathrm{AB}$ ) and frozen in FCS (Invitrogen) containing 10\% DMSO (Sigma-Aldrich) until further experimentation. Intestinal biopsies were incubated for 1 hour at $37^{\circ} \mathrm{C}$ with $1 \mathrm{mg} / \mathrm{ml}$ collagenase IV (MilliporeSigma) in RPMI medium (supplemented with $10 \%$ FCS, $100 \mathrm{U} / \mathrm{ml}$ penicillin-streptomycin, and $0.2 \%$ amphotericin $\mathrm{B}$ [Fungizone]), then forcefully resuspended through an 18.5-gauge needle, filtered with a $70 \mu \mathrm{m}$ cell strainer (Costar), counted, and used for flow cytometry experiments.

Flow cytometry and cell sorting. 200,000 SFMC and PBMC were plated in round-bottom 96-well plates in FACS buffer (PBS containing 2\% FCS [Invitrogen] and 0.1\% sodium azide [Sigma-Aldrich]) and subsequently incubated with surface antibodies: anti-human CD3 BV510 (clone OKT-3, BioLegend), CD4 Alexa Fluor 488 (clone RPAT4, BD), CD8 APC-Cy7 (clone SK1, BD), PD-1 PE (EH12.1, BD) and APC (clone MIH4, BD), CD45RA FITC (clone HI100, BD), CD45RO PB (clone UCHL1, Sony Biotechnology), CCR7 APC (clone G043H7, Sony Biotechnology), TIGIT Percp-eF710 (clone MBSA43, eBioscience), CD69 APC (clone FN50, BD), and CD103 FITC (clone 2G5, Beckman Coulter). Cell death was assessed by using Fixable Viability Dye eFluor 506 (eBioscience). For intracellular staining, after surface staining, cells were fixed and permeabilized by using Fixation and Permeabilization Buffers (eBioscience) and stained with anti-human 
Ki-67 FITC (clone B56, BD), CTLA-4 APC (clone BNI3, BD), and GzmB FITC (clone GB11, BD). For intracellular cytokine production, cells were first stimulated for a total of 4 hours with PMA $(20 \mathrm{ng} / \mathrm{ml}$; MP Biomedicals) and ionomycin (1 $\mu \mathrm{g} / \mathrm{ml}$; Calbiochem); GolgiStop (1/1500; BD Biosciences) was added for the last 3.5 hours of culture. Afterwards, cells were incubated with surface antibodies and then fixed, permeabilized, and intracellularly stained with anti-human GzmB FITC, IFN- $\gamma$ PE-Cy7 (clone 4S.B3, BD), and TNF- $\alpha$ FITC (clone Mab11, BioLegend). In the gut of IBD patients, cells were stained with CD3 BV510, CD4 APC (clone RPA-T4, eBioscience), CD8 $\alpha$ PB (RPAT8, Sony Biotechnology), TCR- $\gamma \delta$ PE (Beckman Coulter), CD69 FITC (clone FN50, BD), and PD-1 Percp-Cy5.5 (clone EH12.2H7, Sony Biotechnology) monoclonal antibodies. In some experiments, after surface staining, cells were sorted by flow cytometry with FACS Aria III (BD Biosciences) to perform additional assays.

Cell cultures. In some experiments, $\mathrm{PD}-\mathrm{1}^{-} \mathrm{CD} 8^{+} \mathrm{T}$ cells from SF-JIA were sorted by BD FACSARIA III and plated in the presence of antiCD3/CD28 (Dynabeads Human T-Activator CD3/CD28, Thermo Fisher Scientific) at a 1:5 ratio (1 bead to 5 cells). After 40 hours, cells were incubated for 4 hours with GolgiStop (1/1500; BD Biosciences) and stained for anti-human PD-1, IFN- $\gamma$, and GzmB antibodies after fixation and permeabilization. In other experiments, SF-derived PD-1 $1^{+}$ and $\mathrm{PD}-\mathrm{1}^{-} \mathrm{CD} 8^{+} \mathrm{T}$ cells were sorted and plated with Dynabeads at a 1:50 ratio in the absence or presence of $10 \mu \mathrm{g} / \mathrm{ml}$ anti-PD-1 agonist (Recombinant Human PD-L1/B7-H1 Fc Chimera Protein, R\&D). After 40 hours, cells were incubated for 4 hours with GolgiStop (1/1500; BD Biosciences) and stained with anti-human PD-1, IFN- $\gamma$, and GzmB antibodies after fixation and permeabilization.

Whole-transcriptome sequencing and analysis. Total RNA was isolated using the RNAeasy Plus Universal Mini Kit (QIAGEN), as specified by the manufacturer's instructions, and stored at $-80^{\circ} \mathrm{C}$. RNA yield was assessed by the Qubit RNA BR Assay Kit (Thermo Fisher Scientific), and then integrity was determined by Bioanalyzer. mRNA was selected using the Poly(A) Purist MAG Kit (Life Technologies, Thermo Fisher Scientific, AM 1922) and additionally purified with an mRNA-ONLY Eukaryotic mRNA Isolation Kit (Epicentre). Transcriptome libraries were then constructed using the SOLiD Total RNA-seq Kit (Applied Biosystems, Life Technologies) and sequenced using the $5500 \mathrm{~W}$ Series Genetic Analyzer to produce reads that were $40 \mathrm{bp}$ long. Sequencing reads were mapped against the reference human genome (hg19, NCBI37) using BWA (-c - $25-\mathrm{k}$ $2-n$ 10) (60). Data were analyzed using DEseq2 (61) and custom Perl and R (www.r-project.org) scripts. PCA was performed by selecting variable genes with fold changes between samples on the 15th and 85th quantiles of at least $1 \log _{2}$ reads per kilobase million (RPKM) and expression of at least $1 \log _{2}$ RPKM in the sample with maximal expression. Hierarchical clustering was performed using unsupervised Pearson's correlation of the variably expressed genes with a minimum of $2 \log _{2}$ fold change between samples with the highest and lowest expression and a minimum of $2 \log _{2}$ RPKM expression values in the sample with the highest expression. Differentially expressed genes with an adjusted $P$ value of less than 0.05 , base mean greater than 2 , and $\log _{2}$ fold change of at least 1 are shown as red dots in log ratio mean average (MA) plots (Figure 1E). For K-means clustering, genes with fold change between samples on the 20th and 80th quantiles of at least $1.5 \log _{2}$ RPKM and expression of at least $1 \log _{2}$ RPKM in the sample with the maximal expression are shown. Path- way enrichment analysis was performed using ToppGene Suite (62), a publicly available online portal. Pathways were considered significantly enriched when the $P$ value corrected for multiple hypothesis testing using Bonferroni's method was less than 0.05. GSEA (17) was used to assess whether specific signatures were significantly enriched in the $\mathrm{PD}-1^{+}$or $\mathrm{PD}-1^{-}$subset. One thousand random permutations of the phenotypic subgroups were used to establish a null distribution of enrichment score against which a normalized enrichment score and FDR-corrected $q$ values were calculated. Gene sets were either obtained by analyzing raw data using GEO2R (NCBI tool) or downloaded from the Molecular Signature Database (Broad Institute software). In particular, the following data sets were used: exhaustion signature, gene set GSE24081; effector CD8 ${ }^{+}$T cell signature, gene set GSE4142; proliferating cell signature, downloaded from the KEGG pathway database (http://www.genome.jp/kegg/ pathway.html); and Trm cell signature, gene set GSE39152.

Validation of whole-transcriptome sequencing. Total RNA was extracted from PD- $1^{+}$and $\mathrm{PD}-\mathrm{1}^{-} \mathrm{CD} 8^{+} \mathrm{T}$ cells from SF-JIA and PB-HC using the AllPrep DNA/RNA/miRNA Universal Kit (QIAGEN) according to the manufacturer's instructions. RNA was reverse transcribed with iSCRIPT cDNA Synthesis Mix (Bio-Rad, catalog 170-8891) using the C1000 Thermal Cycler (Bio-Rad). Quantitative reverse-transcription PCR (qRT-PCR) was performed using SYBR SelectMaster Mix (Thermo Fisher Scientific, catalog 4472919) with the Quantstudio TM 12K Flex Real-time PCR System (Thermo Fisher Scientific). PCR cycling conditions were performed for all samples as follows: $95^{\circ} \mathrm{C}$ for 10 minutes, followed by 40 cycles at $95^{\circ} \mathrm{C}$ for 15 seconds and $60^{\circ} \mathrm{C}$ for 1 minute. The primers used were the following: CCR1, $5^{\prime}$-AGTACCTGCGGCAGTTGTTC-3' (forward), 5'- AAGGGGAGCCATTTAACCAG-3' (reverse); CCL4, 5'-CTGCTCTCCAGCGCTCTC-3' (forward), 5'-ACCACAAAGTTGCGAGGAAG-3' (reverse); GzmB, 5'-GAGACGACTTCGTGCTGACA-3' (forward), 5'-GTCGGCTCCTGTTCTTTGAT-3' (reverse); TOP2A, 5'-TTGTGGAAAGAAGACTTGGCTA-3' (forward), 5'-TGTTCATCTTGTTTTTCCTTGG-3' (reverse). PCR reactions for each template were done in duplicate in a MicroAmp Fast Optical 96-well reaction plate $(0.1 \mathrm{ml})$. The comparative CT method was used to determine gene expression in $\mathrm{PD}-1^{+} \mathrm{CD} 8^{+} \mathrm{T}$ cells relative to the value observed in $\mathrm{PD}-\mathrm{1}^{-} \mathrm{CD} 8^{+} \mathrm{T}$ cells using $\mathrm{B} 2 \mathrm{M}$ as a normalization control.

Seahorse assays. $\mathrm{PD}-1^{+}$and $\mathrm{PD}-\mathrm{1}^{-} \mathrm{CD} 8^{+} \mathrm{T}$ cells from SF-JIA were sorted and plated in XF-24 Cell Culture Microplates (Seahorse Bioscience) in XF Base Medium Minimal DMEM (0 mM glucose) supplemented with $2 \mathrm{mM}$ L-glutamine and $1 \mathrm{mM}$ sodium pyruvate. ECAR was measured under basal conditions and in response to $30 \mathrm{mM}$ glucose on the Seahorse XF24 Extracellular Flux Analyzer (Seahorse Bioscience). ECAR for each time point was normalized to ECAR levels measured in the negative control wells filled with XF Base Medium alone. Cell ability to respond to glucose (glycolysis) was calculated as ECAR under $30 \mathrm{mM}$ glucose conditions minus ECAR measured when 2-deoxyglucose (2-DG) glycolysis inhibitor was added.

Double immunohistochemistry. Frozen sections $(6 \mu \mathrm{m})$ of lesional skin biopsies of $\mathrm{AD}$ patients were fixed in acetone plus $\mathrm{H}_{2} \mathrm{O}_{2}(0.1 \%)$ for 10 minutes and then incubated for 30 minutes in $10 \%$ horse serum in 1\% BSA/PBS solution. After blow-off, sections were incubated with primary antibodies: mouse anti-human CD8 (Dako, catalog M7103, 1:100) or mouse anti-human PD1 (AbCam, catalog ab52587, 1:50) in $1 \%$ horse serum, $1 \% \mathrm{BSA} / \mathrm{PBS}$ for 1 hour at room temperature (RT), and 
then with a biotinylated anti-mouse IgG (Vector, catalog BA-2000, 1:300) for 30 minutes at RT. Afterwards, slides were incubated in $10 \%$ sheep serum for 30 minutes and then with the second primaries: mouse anti-human CD69-FITC (Miltenyi Biotec, catalog 130-092166, 1:50) or mouse anti-human CD8-FITC (Dako, catalog F0765, 1:100) in $1 \%$ sheep serum, $1 \%$ BSA/PBS for 1 hour at RT. Sections were then incubated with a sheep anti-FITC-AP antibody (Roche, catalog 14973500, 1:300) in ABC-HRP solution (ABC-HRP Kit, Vectastain, catalog PK-6100) for 30 minutes at RT. Slides were stained with Vector Blue Substrate Kit (Vector, catalog SK-5300) to detect alkaline phosphatase activity, and Levamisole (Dako, catalog X3021) was added to block endogenous AP during the Fast Blue incubation. The reaction was stopped after monitoring for the desired staining intensity under the microscope ( 10 minutes) in demi-water. Slides were stained subsequently with AEC chromogen (AEC Staining Kit, MilliporeSigma, catalog AEC101) to detect peroxidase activity until the desired color development was reached ( $\sim 5$ minutes). Slides were finally covered with a water base-mounting solution (Imsol Mount) and then hard mounted in Entellan (Merck, catalog HX399193). Single staining with anti-human CD8 antibody was performed in nonlesional skin sections from the same $\mathrm{AD}$ patients, following the protocol with the $\mathrm{ABC}-\mathrm{HRP}$ kit and AEC detection method described above. Sections were counterstained with Mayer's Hematoxylin before mounting.

Next-generation TCR- $\beta$ sequencing analysis. TCR- $\beta$ chain sequencing was performed as previously described (63). A total of 100,000900,000 PD $-1^{+}$and PD- $1^{-} \mathrm{CD} 8^{+}$T cells were isolated from SF-JIA ( $n=$ 4). Cells were washed with PBS and frozen at $-80^{\circ} \mathrm{C}$. Total RNA was isolated using the RNeasy Mini Kit (QIAGEN) following the instructions of the manufacturer. cDNA was synthesized using the SMARTer RACE cDNA Amplification Kit (Clontech). Amplification of the TCR- $\beta$ VDJ region was performed using previously described primers and amplification protocols (64). PCR products were analyzed with a QIAxcel Advanced System (QIAGEN). Upon successful amplification, end repair was performed with the ClaSeek Library Preparation Kit, Illumina compatible (Thermo Scientific), according to the recommendations of the manufacturer. Subsequently, TruSeq Barcode Adapters (Illumina) were ligated using the ClaSeek Ligation Mix (Thermo Scientific). Cleanup of the samples was performed with the Agencourt AMPure XP system (Beckman Coulter). Next-generation sequencing was performed on an Ilumina MiSeq system 500 ( $2 \times 250$ bp) (Illumina). Sequencing data were analyzed with the MiTCR program (65). The MiTCR output file was used to calculated the Simpson's index, as follows:

$$
D=\frac{\sum n(n-1)}{N(N-1)}
$$

(Equation 1)

in which $D=$ Simpson's index, $n=$ total number of specific sequences, and $N=$ total number of all sequences. Data are presented as the Simpson's reciprocal index of diversity $=1 / D$. A Simpson's reciprocal index of diversity equal to 1 indicates monoclonality, whereas the higher the value, the greater the diversity.
Telomere length. DNA was collected using the AllPrep DNA/RNA Plus Kit (QIAGEN) from PD $-1^{+}$and PD-1 ${ }^{-}$CD $8^{+}$T cells from SF-JIA. Telomere repeats (TTAGGG) (Telomere Length Assay Kit, catalog 12 209136 001, Roche Applied Science) were quantified using qualitative qPCR. qPCR was modified with synthetic standard of telomere repeats, enabling the absolute quantification of telomere length, which was additionally normalized by the housekeeping gene (36B4), quantified based on the same method (66). Telomere length is represented according to the absolute number of the quantified bps.

Statistics. For more than 2 groups, 1-way ANOVA was used. As post hoc analysis, Bonferroni's multiple comparison test was performed. Two-tailed paired sample $t$ test was used to compare matched samples, while unpaired Student's $t$ test was applied when samples were not matched. Data are shown as mean \pm SD. $P$ values below 0.05 were considered significant. Statistical analysis was performed using GraphPad Prism (GraphPad Software).

Study approval. Patients were enrolled after giving written, informed consent either directly and/or from parents/guardians if they were under 12 years of age. For informed consent, the nature and possible consequences of the study were explained. Biological samples were crosssectionally collected through a general Biobank protocol (IRB approval: Pharmachild n.11-499/C). The study was approved by The Medical Research Ethics Committee of University Medical Center Utrecht and was conducted in accordance with the Declaration of Helsinki.

\section{Author contributions}

A Petrelli and FW were responsible for experimental design, data interpretation, and manuscript preparation. A Petrelli, GM, DPHVK, MMVDW, BG, EM, and NV contributed to acquiring and analyzing data. JCB, DH, BO, PJC, SJV, BJP, ES, A Pandit, and MM contributed to data interpretation and manuscript preparation.

\section{Acknowledgments}

We are grateful to Joost Swart and Sytze de Roock for their help with patient database and sample management. We are thankful to the Epigenomics Facility at University Medical Center Utrecht, which performed whole-transcriptome sequencing. A Petrelli has received funding from the 7th Framework Programme of the EU, SP3-People, Support for Training and Career Development for Researchers (Marie Curie), Network for Initial Training (ITN), FP7-PEOPLE2011-ITN, under Marie Skłodowska-Curie grant agreement n. 289903. FW is supported by a VIDI grant (91714332) from the Netherlands Organization for Scientific Research (NWO, ZonMW) and the Dutch Arthritis Foundation "Reumafonds" (12-2-404).

Address correspondence to: Femke van Wijk, Laboratory of Translational Immunology, Wilhelmina Children's Hospital, University Medical Centre Utrecht, Lundlaan 6, 3584 EA Utrecht. Phone: 31.0.88.7568958; Email: f.vanwijk@umcutrecht.nl.

A Petrelli's present address is: Diabetes Research Institute (DRI), San Raffaele Hospital, Milan, Italy.
1. Arron JR, Townsend MJ, Keir ME, Yaspan BL, Chan AC. Stratified medicine in inflammatory disorders: From theory to practice. Clin Immunol. 2015;161(1):11-22.
2. Petrelli A, van Wijk F. CD8(+) T cells in human autoimmune arthritis: the unusual suspects. Nat Rev Rheumatol. 2016;12(7):421-428.

3. Babbe H, et al. Clonal expansions of CD8(+) T cells dominate the $\mathrm{T}$ cell infiltrate in active multiple sclerosis lesions as shown by micromanipulation and single cell polymerase chain reaction. J Exp Med. 2000;192(3):393-404. 
4. Cho BA, et al. Characterization of effector memory CD8+ $T$ cells in the synovial fluid of rheumatoid arthritis. J Clin Immunol. 2012;32(4):709-720.

5. Hunter PJ, et al. Biologic predictors of extension of oligoarticular juvenile idiopathic arthritis as determined from synovial fluid cellular composition and gene expression. Arthritis Rheum. 2010;62(3):896-907.

6. Costello P, Bresnihan B, O'Farrelly C, FitzGerald O. Predominance of CD8+ Tlymphocytes in psoriatic arthritis. J Rheumatol. 1999;26(5):1117-1124.

7. Carvalheiro H, Duarte C, Silva-Cardoso S, da Silva JA, Souto-Carneiro MM. CD8+ T cell profiles in patients with rheumatoid arthritis and their relationship to disease activity. Arthritis Rheumatol. 2015;67(2):363-371.

8. Wehrens EJ, et al. Functional human regulatory $T$ cells fail to control autoimmune inflammation due to $\mathrm{PKB} / \mathrm{c}$-akt hyperactivation in effector cells. Blood. 2011;118(13):3538-3548.

9. Haufe $S$, et al. Impaired suppression of synovial fluid CD4+CD25- $\mathrm{T}$ cells from patients with juvenile idiopathic arthritis by CD4+CD25+ Treg cells. Arthritis Rheum. 2011;63(10):3153-3162.

10. Li S, et al. Expression of TIM-3 on CD4+ and $\mathrm{CD} 8+\mathrm{T}$ cells in the peripheral blood and synovial fluid of rheumatoid arthritis. APMIS. 2014;122(10):899-904.

11. Speiser DE, Utzschneider DT, Oberle SG, Münz C, Romero P, Zehn D. T cell differentiation in chronic infection and cancer: functional adaptation or exhaustion? Nat Rev Immunol. 2014;14(11):768-774.

12. Barber DL, et al. Restoring function in exhausted CD8 T cells during chronic viral infection. Nature. 2006;439(7077):682-687.

13. Day CL, et al. PD-1 expression on HIVspecific $\mathrm{T}$ cells is associated with T-cell exhaustion and disease progression. Nature. 2006;443(7109):350-354.

14. Urbani S, et al. PD-1 expression in acute hepatitis $\mathrm{C}$ virus (HCV) infection is associated with HCV-specific CD8 exhaustion. JVirol. 2006;80(22):11398-11403.

15. Topalian SL, et al. Safety, activity, and immune correlates of anti-PD- 1 antibody in cancer. NEngl JMed. 2012;366(26):2443-2454.

16. Raptopoulou AP, et al. The programmed death 1 /programmed death ligand 1 inhibitory pathway is up-regulated in rheumatoid synovium and regulates peripheral $\mathrm{T}$ cell responses in human and murine arthritis. Arthritis Rheum. 2010;62(7):1870-1880.

17. Subramanian A, et al. Gene set enrichment analysis: a knowledge-based approach for interpreting genome-wide expression profiles. Proc Natl Acad Sci USA. 2005;102(43):15545-15550.

18. Quigley M, et al. Transcriptional analysis of HIVspecific CD8+ T cells shows that PD-1 inhibits T cell function by upregulating BATF. Nat Med. 2010;16(10):1147-1151.

19. Luckey CJ, Bhattacharya D, Goldrath AW, Weissman IL, Benoist C, Mathis D. Memory $\mathrm{T}$ and memory $\mathrm{B}$ cells share a transcriptional program of self-renewal with long-term hematopoietic stem cells. Proc Natl Acad Sci USA. 2006;103(9):3304-3309.

20. Kao C, et al. Transcription factor T-bet represses expression of the inhibitory receptor PD-1 and sustains virus-specific $\mathrm{CD} 8+\mathrm{T}$ cell responses during chronic infection. Nat Immunol. 2011;12(7):663-671.

21. Paley MA, et al. Progenitor and terminal subsets of CD8+ T cells cooperate to contain chronic viral infection. Science. 2012;338(6111):1220-1225.

22. Shin $\mathrm{H}$, et al. A role for the transcriptional repressor Blimp-1 in CD8(+) T cell exhaustion during chronic viral infection. Immunity. 2009;31(2):309-320.

23. Buck MD, O'Sullivan D, Pearce EL. T cell metabolism drives immunity. J Exp Med. 2015;212(9):1345-1360.

24. Gubser PM, et al. Rapid effector function of memory $\mathrm{CD} 8+\mathrm{T}$ cells requires an immediate-early glycolytic switch. Nat Immunol. 2013;14(10):1064-1072.

25. Bengsch B, et al. Bioenergetic insufficiencies due to metabolic alterations regulated by the inhibitory receptor PD-1 are an early driver of CD8(+) T cell exhaustion. Immunity. 2016;45(2):358-373.

26. Sathaliyawala T, et al. Distribution and compartmentalization of human circulating and tissue-resident memory $\mathrm{T}$ cell subsets. Immunity. 2013;38(1):187-197.

27. Farber DL, Yudanin NA, Restifo NP. Human memory T cells: generation, compartmentalization and homeostasis. Nat Rev Immunol. 2014;14(1):24-35.

28. Iijima N, Iwasaki A. Tissue instruction for migration and retention of Trm cells. Trends Immunol. 2015;36(9):556-564.

29. Wakim LM, et al. The molecular signature of tissue resident memory CD8 $\mathrm{T}$ cells isolated from the brain. JImmunol. 2012;189(7):3462-3471.

30. Djenidi F, et al. CD8+CD103+ tumor-infiltrating lymphocytes are tumor-specific tissue-resident memory $\mathrm{T}$ cells and a prognostic factor for survival in lung cancer patients. J Immunol. 2015;194(7):3475-3486

31. Watanabe $\mathrm{R}$, et al. Human skin is protected by four functionally and phenotypically discrete populations of resident and recirculating memory T cells. Sci Transl Med. 2015;7(279):279ra39.

32. Kumar BV, et al. Human tissue-resident memory $\mathrm{T}$ cells are defined by core transcriptional and functional signatures in lymphoid and mucosal sites. Cell Rep. 2017;20(12):2921-2934.

33. Skon CN, Lee JY, Anderson KG, Masopust D, Hogquist KA, Jameson SC. Transcriptional downregulation of S1pr1 is required for the establishment of resident memory CD8+ T cells. Nat Immunol. 2013;14(12):1285-1293.

34. Baitsch L, et al. Exhaustion of tumor-specific $\mathrm{CD}^{+} \mathrm{T}$ cells in metastases from melanoma patients. JClin Invest. 2011;121(6):2350-2360.

35. Mackay LK, et al. Hobit and Blimp1 instruct a universal transcriptional program of tissue residency in lymphocytes. Science. 2016;352(6284):459-463.

36. Wolfl M, et al. Activation-induced expression of $\mathrm{CD} 137$ permits detection, isolation, and expansion of the full repertoire of CD8+ $\mathrm{T}$ cells responding to antigen without requiring knowledge of epitope specificities. Blood. 2007;110(1):201-210.

37. Hodes RJ, Hathcock KS, Weng NP. Telomeres in T and B cells. Nat Rev Immunol. 2002;2(9):699-706.
38. McKinney EF, et al. A CD8+ T cell transcription signature predicts prognosis in autoimmune disease. Nat Med.2010;16(5):586-591, 1p following 591.

39. McKinney EF, Lee JC, Jayne DR, Lyons PA, Smith KG. T-cell exhaustion, co-stimulation and clinical outcome in autoimmunity and infection. Nature. 2015;523(7562):612-616.

40. Utzschneider DT, et al. High antigen levels induce an exhausted phenotype in a chronic infection without impairing $\mathrm{T}$ cell expansion and survival. J Exp Med. 2016;213(9):1819-1834.

41. Wherry EJ. T cell exhaustion. Nat Immunol. 2011;12(6):492-499.

42. Pentcheva-Hoang T, Chen L, Pardoll DM, Allison JP. Programmed death- 1 concentration at the immunological synapse is determined by ligand affinity and availability. Proc Natl Acad Sci USA. 2007;104(45):17765-17770.

43. Gros A, et al. PD-1 identifies the patient-specific $\mathrm{CD} 8{ }^{+}$tumor-reactive repertoire infiltrating human tumors. JClin Invest. 2014;124(5):2246-2259.

44. Hong JJ, Amancha PK, Rogers K, Ansari AA, Villinger F. Re-evaluation of PD-1 expression by $\mathrm{T}$ cells as a marker for immune exhaustion during SIV infection. PLoS One. 2013;8(3):e60186.

45. Breton G, et al. Programmed death-1 is a marker for abnormal distribution of naive/memory T cell subsets in HIV-1 infection. J Immunol. 2013;191(5):2194-2204.

46. Whittall T, Peters B, Rahman D, Kingsley CI, Vaughan R, Lehner T. Immunogenic and tolerogenic signatures in human immunodeficiency virus (HIV)-infected controllers compared with progressors and a conversion strategy of virus control. Clin Exp Immunol. 2011;166(2):208-217.

47. Utzschneider DT, et al. T cell factor 1-expressing memory-like CD8(+) T cells sustain the immune response to chronic viral infections. Immunity. 2016;45(2):415-427.

48. Ghoneim HE, et al. De novo epigenetic programs inhibit PD-1 blockade-mediated T cell rejuvenation. Cell. 2017;170(1):142-157.e19.

49. Jiang TT, et al. Programmed death-1 culls peripheral accumulation of high-affinity autoreactive CD4 T cells to protect against autoimmunity. Cell Rep. 2016;17(7):1783-1794.

50. Ruscher R, Kummer RL, Lee YJ, Jameson SC, Hogquist KA. CD8 $\alpha$ a intraepithelial lymphocytes arise from two main thymic precursors. Nat Immunol. 2017;18(7):771-779.

51. Mueller SN, Mackay LK. Tissue-resident memory T cells: local specialists in immune defence. $\mathrm{Nat}$ Rev Immunol. 2016;16(2):79-89.

52. Clark RA. Resident memory T cells in human health and disease. Sci Transl Med. 2015;7(269):269rv1.

53. Henderson LA. Novel 3 dimensional explant method facilitates the study of lymphocyte populations in the synovium and reveals a large population of resident memory $\mathrm{T}$ cells in rheumatoid arthritis. Arthritis Rheum. 2014;66(3):S209.

54. Bommarito D, Hall C, Taams LS, Corrigall VM. Inflammatory cytokines compromise programmed cell death-1 (PD-1)-mediated T cell suppression in inflammatory arthritis through up-regulation of soluble PD-1. Clin Exp Immunol. 2017;188(3):455-466.

55. Riley JL. PD-1 signaling in primary T cells. Immu- 
nol Rev. 2009;229(1):114-125.

56. Odorizzi PM, Pauken KE, Paley MA, Sharpe A, Wherry EJ. Genetic absence of PD-1 promotes accumulation of terminally differentiated exhausted CD8+ T cells. JExp Med. 2015;212(7):1125-1137.

57. Song MY, et al. Protective effects of Fc-fused PD-L1 on two different animal models of colitis. Gut. 2015;64(2):260-271.

58. Kim JH, et al. Programmed cell death ligand 1 alleviates psoriatic inflammation by suppressing IL-17A production from programmed cell death 1-high T cells. J Allergy Clin Immunol. 2016;137(5):1466-1476.e3.
59. Petty RE, et al. Revision of the proposed classification criteria for juvenile idiopathic arthritis: Durban, 1997. J Rheumatol. 1998;25(10):1991-1994.

60. Li H, Durbin R. Fast and accurate short read alignment with Burrows-Wheeler transform. Bioinformatics. 2009;25(14):1754-1760.

61. Love MI, Huber W, Anders S. Moderated estimation of fold change and dispersion for RNA-seq data with DESeq2. Genome Biol. 2014;15(12):550.

62. Chen J, Bardes EE, Aronow BJ, Jegga AG. ToppGene Suite for gene list enrichment analysis and candidate gene prioritization. Nucleic Acids Res. 2009;37(Web Server issue):W305-W311.

63. Delemarre EM, et al. Autologous stem cell transplantation aids autoimmune patients by functional renewal and TCR diversification of regulatory T cells. Blood. 2016;127(1):91-101.

64. Zhou D, Srivastava R, Grummel V, Cepok S, Hartung HP, Hemmer B. High throughput analysis of TCR-beta rearrangement and gene expression in single T cells. Lab Invest. 2006;86(3):314-321.

65. Bolotin DA, et al. MiTCR: software for T-cell receptor sequencing data analysis. Nat Methods. 2013;10(9):813-814.

66. O'Callaghan N, Dhillon V, Thomas P, Fenech M. A quantitative real-time PCR method for absolute telomere length. BioTechniques. 2008;44(6):807-809. 